\title{
Enhancing Gas Response Characteristics of Mixed Metal Oxide Gas Sensors
}

\author{
Chandran Balamurugan, Sun-Ju Song, and Ho-Sung Kim ${ }^{\dagger}$ \\ School of Materials Science and Engineering, Chonnam National University, Gwangju 61186, Korea \\ (Received November 10, 2017; Revised December 14, December 20, 2017; Accepted December 21, 2017)
}

\begin{abstract}
Semiconducting nanomaterials have attracted considerable interest in recent years due to their high sensitivity, selectivity, and fast response time. In addition, for portable applications, they have low power consumption, lightweight, simple in operation, a low maintenance cost. Furthermore, it is easy to manufacture microelectronic sensor structures with metallic oxide sensitive thin layers. The use of semiconducting metal oxides to develop highly sensitive chemiresistive sensing systems remains an important scientific challenge in the field of gas sensing. According to the sensing mechanisms of gas sensors, the overall sensor conductance is determined by surface reactions and the charge transfer processes between the adsorbed species and the sensing material. The primary goal of the present study is to explore the possibility of using semiconducting mixed metal oxide nanostructure as a potential sensor material for selective gases.
\end{abstract}

Key words : Chemiresistive sensor, Mixed metal oxide, $p$ and n-type electrical properties, Interface, Gas sensors

\section{Introduction}

$\mathrm{T}$ he control of contaminated air sources is a current severe environmental problem, where recent significant global industrialization and modern human activities have led to the presence of an increased concentration of a wide range of toxic gases and organic pollutants in air and environment. The air pollutants can be divided into four significant categories (i) gaseous pollutants (e.g. $\mathrm{CO}, \mathrm{NO}_{\mathrm{x}}$ ) and volatile organic compounds; (ii) persistent organic pollutants (e.g. dioxins), (iii) heavy metals such as $\mathrm{Pb}$ and $\mathrm{Hg}$ and (iv) particulate matter. Among these pollutants, many toxicological and epidemiological studies established adverse health effects of toxic gases in the air. Human exposed to high concentration of toxic air can deaden the sense of smells. ${ }^{1)}$ Health effect also has often found in human longer exposed to the low-level concentration. Depending on the ppm level, the detected gas could cause hypesthesia, headache or even it blocks the transfer of oxygen to the blood cell in the human systems. ${ }^{2}$ ) The control of contamination in the air environment also becomes increasingly important because it leads to the depletion of ozone layer, global warming, and climate change. Therefore, the earlier detection and monitoring of these toxic gases and degradation of organic pollutants from the air and environment has received intense research.

A sensor is a device that receives a physical, chemical or biological signal and converts it into an electric signal that

\footnotetext{
Corresponding author: Ho-Sung Kim

E-mail : symmetry@jnu.ac.kr

Tel : +82-62-530-1707 Fax : +82-62-530-1699
}

is compatible with electronic circuits. Another term with a meaning similar to a sensor is the transducer. Sometimes transducer is used as a synonym for a sensor. A sensor may be composed by a series of transducers responding in the end with an electrical output, in which case, given the above definition, the last transducer in the series could also be termed a sensor. Gas sensors will be defined as "a device which provides an electrical output in response to the change in partial pressure of a gas". In addition to the conductivity change of gas-sensing material, the detection of sensing reaction can be performed by measuring the changes in capacitance, work function, mass, optical characteristics or reaction energy released by the gas/solid interaction.

In order to improve environmental safety, there is a great interest and need to implementing sensing devices in carrying out the optimization of combustion reactions in the emerging transport industry, domestic as well as industrial and biological applications. For example, $\mathrm{H}_{2} \mathrm{~S}$ gas is widely used in several industrial activities, and it is produced as a common by-product of more than 70 manufacturing processes. ${ }^{3)}$ It is also typically released during the decay of the natural wastes. Besides, human bodies also produced the small amount of $\mathrm{H}_{2} \mathrm{~S}$ and acted as a signalling molecule. For example, $\mathrm{H}_{2} \mathrm{~S}$ is physiologically produced by cystathionine$\beta$-lyase (CSE) and cystathionine- $\beta$-synthase (CBS), which is predominant, associated with the brain and vascular smooth muscle cells in the human body. ${ }^{4)}$ Therefore, monitoring and detection of low-level $\mathrm{H}_{2} \mathrm{~S}$ concentration devices is a crucial important requirement in various fields. The $\mathrm{CO}_{2}$ sensors are examples of devices that have found multiple uses; they are needed for indoor air quality operations as well as for incubators in food storage and processing. The 
low-temperature sensing of CO plays an important role in solving the growing environmental problems stemming from $\mathrm{CO}$ emission from automobiles, and industrial processes, etc. ${ }^{5)}$ The application of SMO sensors for alcohol detection on the breath is an efficient way to aid police in apprehending drink driving offenders. ${ }^{6}$ Ammonia $\left(\mathrm{NH}_{3}\right)$ is one of the most commonly used substances in many chemical process industries, refrigeration systems and fertilizer factories, etc. Nevertheless, human exposure to higher concentrations, it can cause burns on the skin, eyes, throat, or lungs causing permanent blindness and lung disease. ${ }^{7)}$ In addition, ammonia aerosols have a severe environmental pollution such as acid rain and photochemical smog. In order to control such emissions, it is necessary to develop rugged and reliable $\mathrm{NO}$ gas sensing devices that can be put on the various emitting sites are required. The hydrogen sensors are needed in the rocket propulsion industry as hydrogen propellant leaks pose significant safety risks. In addition, the automotive industry routinely monitors the air to fuel ratio in vehicles with oxygen sensors. The automotive industry also has interest in $\mathrm{NO}_{\mathrm{x}}$ sensors because nitrogen oxide (nitrogen mono oxide (NO) and nitrogen dioxide $\left(\mathrm{NO}_{2}\right)$ together referred to as $\left.\mathrm{NO}_{\mathrm{x}}\right)$ is a typical air pollutant, which causes environmental problems and arises principally from when fuel burns at high temperatures. ${ }^{8)}$ They can travel great distances from their emission source and result in ozone, smog, and particulate matter far from the actual source of pollution. In spite of many efforts are currently made to reduce $\mathrm{NO}_{\mathrm{x}}$ emission either by the optimization and control of the combustion reaction or by the modern ultra-lean burn engine system under newly developed $\mathrm{NO}_{\mathrm{x}}$ storage catalyst conditions. However, this new engine system requires a reliable high-performance $\mathrm{NO}_{\mathrm{x}}$ sensor to be installed at the points before and after the $\mathrm{NO}_{\mathrm{x}}$ storage catalyst in order to improve its efficiency. ${ }^{9)}$ Hydrocarbons are also a precursor to ground level ozone, and some types of hydrocarbons are known to be toxic and widely used as a common fuel for industrial and domestic purposes is potentially hazardous because of its explosive nature on account of leakage. Hence, it is necessary to develop suitable sensors for the detection of hydrocarbon. Therefore, detection of lowlevel toxic gas concentration is a crucial imperative requirement in various fields, such as industrial areas, the human body, and biological environment.

This increased demand has resulted in the accelerated development of new sensing materials and sensor technologies over the last decade. ${ }^{10,11)}$ Developing gas sensors for harsh industrial environments is quite challenging because the sensors must be both highly sensitive and selective; i.e., in the presence of multiple oxidizing and reducing gases.5) To determine these endogenous gases in the environment, spectroscopic, chromatography and their combination systems have worked most effectively. However, the operation of this system is a more complicated process, as it involves a multi-step protocol starting from sampling to the final determination. ${ }^{12)}$ Furthermore, the high cost sophisticated spectroscopic and analytical chromatography systems hinder the monitoring and detection of the gases in various site. As an alternative to the advanced tool, the chemiresistive metal oxide based semiconductors have been widely investigated for gas sensing applications. Therefore, gas sensing properties of mixed metal oxide nanostructures assembled by nanoparticles are reviewed in this work. The attention will be focused on the possibility of using semiconducting mixed metal oxide nanopowder as a potential selective sensor material for various gases. ${ }^{13)}$

\section{Oxide Materials for Gas Sensor}

\subsection{Semiconductor metal oxide based gas sensor}

Semiconductor metal oxide (SMO) based gas sensor devices play an important role in human health and environment safety. Over the years, extensive research and fabrication efforts have been carried out for the development of a single metal oxide semiconductor gas sensor. ${ }^{14)}$ Among the SMOs used for gas sensors, $\mathrm{Nb}_{2} \mathrm{O}_{5}, \mathrm{ZnO}, \mathrm{CuO}, \mathrm{NiO}$, and $\mathrm{SnO}_{2}$ have been widely studied as the best gas sensing materials to detect reducing gases (such as $\mathrm{H}_{2}$, $\mathrm{CO}$, hydrocarbon, and alcohol) as well as oxidizing gases (such as oxygen and NOx). ${ }^{6}$ The sensitivity of gas sensors is directly proportional to the surface-area-to-volume ratio of the exposed sensing surface. ${ }^{5}$ ) The principle of operation of these metal-oxide based gas sensor relies upon the change in electrical conductivity due to the interaction between the gases in the environment and oxygen in the grain boundaries.

\section{2. $n$ and p-type semiconductor based gas sensor}

From the material point of view, sensor materials are classified as n-type or p-type, depending on whether they show an increase or decrease in electrical resistance when they are exposed to reducing or oxidizing test gases. (Referring as example to an n-type semiconductor oxide). ${ }^{15)}$ The resistance of the sensing layer with an n-type behavior decreases when the surface is exposed to electron-donating gases, such as CO or hydrocarbons. On the other hand, the resistance increases in the presence of electron-withdrawing gases such as $\mathrm{NO}_{2}$, even to values exceeding the detection limits of conventional circuitry. ${ }^{16)}$ This resistance variation can be easily observed and used to detect chemical species in the ambient.5) The most of n-type sensor materials such as $\mathrm{SnO}_{2}, \mathrm{ZnO}, \mathrm{In}_{2} \mathrm{O}_{3}, \mathrm{Fe}_{2} \mathrm{O}_{3}$ and $\mathrm{WO}_{3}$ have been extensively used as an excellent catalyst to promote selective oxidation of various volatile organic compounds. In contrast, the gas sensor fabricated using p-type oxide semiconductors such as $\mathrm{NiO}, \mathrm{CuO}, \mathrm{Co}_{3} \mathrm{O}_{4}, \mathrm{Cr}_{2} \mathrm{O}_{3}$ and $\mathrm{Mn}_{3} \mathrm{O}_{4}$ to date have received relatively little attention, and the related research to fabricate such gas sensor is still in the early stage of development. ${ }^{17)}$ However, this sensor suffers from disadvantages owing to its selectivity for specific gases in a harsh environment and operating temperature. A selective sensor must be able to distinguish among the different gases or respond to only one of the gases in the mixture. ${ }^{5,18)}$ 
In short, low detection limit and fast response and recovery of the gas sensor materials should be further improved for successful operation. An additional temperature change could be caused by catalytic reactions, occurring at the metal oxide surface during interaction with gas. ${ }^{19)}$ Various studies have been performed to reduce the sensor operating temperature, including the doping of noble metals as a catalyst to reduce the operating temperature and improve the sensor life. ${ }^{20)}$ In order to improve the gas selectivity of the metal oxide, intense research efforts have been devoted to pursuing new material that may be exploited for achieving high gas response characteristics of sensor devices. Recently, the latter has been improved by co-synthesis with other oxides, leading to thermally stable and highly sensitive nanoparticle layers. For some analytes, the selectivity is improved by the formation of specific crystal planes and phases that significantly facilitate the reliable detection of certain gases. Therefore, the alternative oxide structure is attracting significant research attention owing to its importance in practical applications. ${ }^{3)}$

\subsection{Mixed metal oxide gas sensor}

In recent years, mixed metal oxides nanostructures have received much attention for various technological applications in science and technology, ${ }^{21)}$ since their functional metal oxidation states are crucial for determining the electronic, magnetic, and redox properties. The synthesis of suitably mixed metal oxides to carry out complex functions is one of the most important topics in the research field of sensors, catalysis, batteries, capacitors etc. ${ }^{22,23)}$ In these potential applications, the mixed metal oxide should exhibit features such as a suitable combination of a polyfunctional metal catalyst with textural properties (crystallinity, porosity, morphology, and defects structure). ${ }^{24)}$ It has been reported that various binary and ternary mixed metal oxide nanostructured systems exhibit a selective higher response to specific gases at low operating temperatures as compared to single metal oxide materials. ${ }^{25)}$ Accordingly, perovskitetype $\left(\mathrm{ABO}_{3}\right)$ metal oxides, such as rare earth with one or more transition metals have been considered as suitable candidates for the selective detection of specific gases under a harsh environment and as a promising alternative to high-cost noble metals. ${ }^{26)}$

\section{3. $\mathrm{ABO}_{3}$ Rare-Earth Perovskite Gas Sensor}

Rare-earth perovskite semiconductors denoted as $\mathrm{ABO}_{3}$ (A = rare earth), where A stands for a lanthanide or an alkaline earth element and B represents a transition metal. These compounds are highly relevant chemical and physical properties for technological applications such as a gas sensor, electrodes for solid oxide fuel cells (SOFC), catalysts, among others. ${ }^{5,27,28)}$ In this structure, the A cation is a large rare earth, alkali, and alkaline earth cation, which fits into the dodecahedral interstices, and the $\mathrm{B}$ cation is a catalytically active $3 \mathrm{~d}$ or $4 \mathrm{~d}$ transition metal ion, which is 6 -fold coordinated with the oxygen anions. The stability of the mixed oxidation states $\left(\mathrm{B}^{3+}-\mathrm{B}^{2+}\right)$ and unusual oxidation states of the perovskite offers significantly favored catalytic reactions. Its electrical property is related to the intrinsic oxygen deficiency, have been considered as suitable candidates for the selective detection of specific gases under a harsh environment and as a promising alternative to highcost noble metals. However, the synthesis conditions strongly influenced the structural characteristics as well as the catalytic activity of the $\mathrm{ABO}_{3}$ samples. Furthermore, the garnet phase $\left(\mathrm{A}_{3} \mathrm{~B}_{5} \mathrm{O}_{12}\right)$ is more thermodynamically stable than the $\mathrm{ABO}_{3}$. Since past decades, several investigation groups have used number of preparative methods to obtain garnet-free perovskite-type materials. ${ }^{529)}$ Moreover, perovskite materials are generally synthesized via a solid-state method. Nevertheless, other chemical routes have been explored such as an aqueous solution method, sol-gel route, sol-precipitation process and glycine nitrate $(\mathrm{G} / \mathrm{N})$ plus EDTA route. These synthesis routes allowed obtaining products with homogeneity, high porosity and specific morphologies all of which to a great relevance due to its potential applications. ${ }^{15)}$

\subsection{GdInO $\mathrm{O}_{3}$ perovskite gas sensor}

Among the perovskite semiconductors, $\mathrm{GdInO}_{3}$ belong to the $\mathrm{ABO}_{3}$ structure have evoked a lot of interest in recent years due to their promising properties, such as high conductivity and catalytic activity. Suitable substitution can control both these features at $\mathrm{Gd}$ and $\mathrm{In}$ sites of $\mathrm{GdInO}_{3}{ }^{30)} \mathrm{It}$ has been found that ferroelectricity on these compounds is the interplay of bending of the $\mathrm{BO}_{5}$ trigonal bipyramid and the different A-O bond lengths along the c-axis. Moreover, $\mathrm{GdInO}_{3}$ is a vital prototype material that has hexagonal $\mathrm{P}_{3} \mathrm{~cm}$ crystallography. $\mathrm{GdInO}_{3}$ have been extensively investigated as an alternative solid oxide fuel cell (SOFC) electrode materials owing to their unique structural-dependent oxygen conductivity ${ }^{5,31)}$ and it also exhibits good oxidation and reduction properties over a wide range of temperatures, and can be used in several potential applications such as gas separators, sensor, catalysis, etc. These potential applications of the $\mathrm{GdInO}_{3}$ materials depend mainly on the extent of structure, morphology, and controlled particle size. On the basis of gas sensing mechanism, redox reaction involves at the surface leading to a change in the depletion layer of the grains which in turn changes the electrical resistance of the sensor. The overall sensor conductance is determined by the surface reactions and the charge transfer processes between the adsorbed species and the semiconductor surface. Adsorption being a surface effect, surface area plays an important role in the sensing mechanism. Therefore, hierarchically nanostructured porous materials are promising candidates because their special structures are caused by particles of very small dimensions in comparison with the corresponding bulk counterparts. Because, nanosized materials large fraction of atoms is present at the surface and these atoms are greatly facilitated gas diffusion and mass transport on the sensor surface 

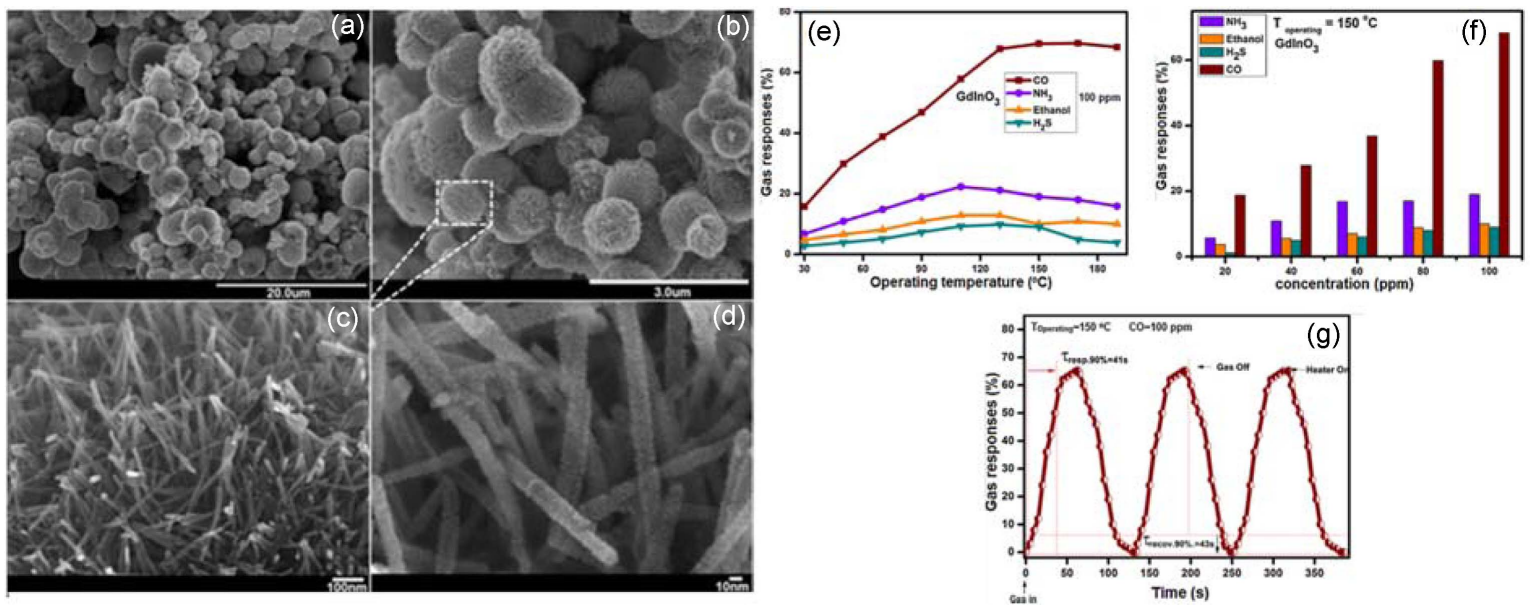

Fig. 1. Low and high SEM images of (a-d) the annealed $\mathrm{GdInO}_{3}$ nanopowder, (e) CO response of the $\mathrm{GdInO}_{3}$ as a function of operating temperature, (f) selectivity of the $\mathrm{GdInO}_{3}$ based gas sensors to different concentration of $\mathrm{CO}$ at optimum operating temperature (g) Response and recovery time of the $\mathrm{GdInO}_{3}$. Reprinted with permission from reference. ${ }^{5)}$

and enhance the gas sensing properties of semiconducting oxides. Besides high temperature solid-state preparation, perovskite nanocrystalline materials have been prepared using various simple solution-based chemical methods. Specifically, the hydrothermal approach has been considered as the most successful method to synthesize numerous versatile morphological nanostructures owing to its low reaction temperature and better control of physicochemical properties of nanostructured materials compared to other synthesis techniques. Therefore, we synthesized mesoporous hexagonal $\mathrm{GdInO}_{3}$-based semiconductor perovskite metal-oxide nanostructure using a single-step hydrothermal method with gadolinium nitrate and indium nitrate as precursors. The gas response characteristic of the prepared nanostructure is investigated with various combustible gases such as $\mathrm{CO}$, gasoline, $\mathrm{C}_{2} \mathrm{H}_{5} \mathrm{OH}, \mathrm{H}_{2} \mathrm{~S}$, and $\mathrm{NH}_{3}$, at different operating temperatures. Fig. 1(a-d) shows the meso- porous crystalline $\mathrm{GdInO}_{3}$ nanostructure has been determined to be effective for the detection of $\mathrm{CO}$ at $150^{\circ} \mathrm{C}$. In addition, the author also investigated the effects of interfering gases on the response properties of the mesoporous crystalline $\mathrm{GdInO}_{3}$ as shown in Fig. 2(e-g). The schematic of sensor element and setup used for the gas response studies is as shown in Fig. 2.

\subsection{Reduced graphen oxide loaded $\mathrm{GdInO}_{3}$ per- ovskite semiconductors}

In order to enhance the gas sensitivity and reduce the operating temperature of perovskite metal-oxide based sensor, many modifications are commonly used such as loading with suitable additives, anionic doping, coupling, sensitization, and making defect from the modified synthesis process, etc. For this reason, we prepared reduced graphen oxide loaded $\mathrm{GdInO}_{3}$ ( $\mathrm{rGO} / \mathrm{GdInO}_{3}$ ) nanocomposites by

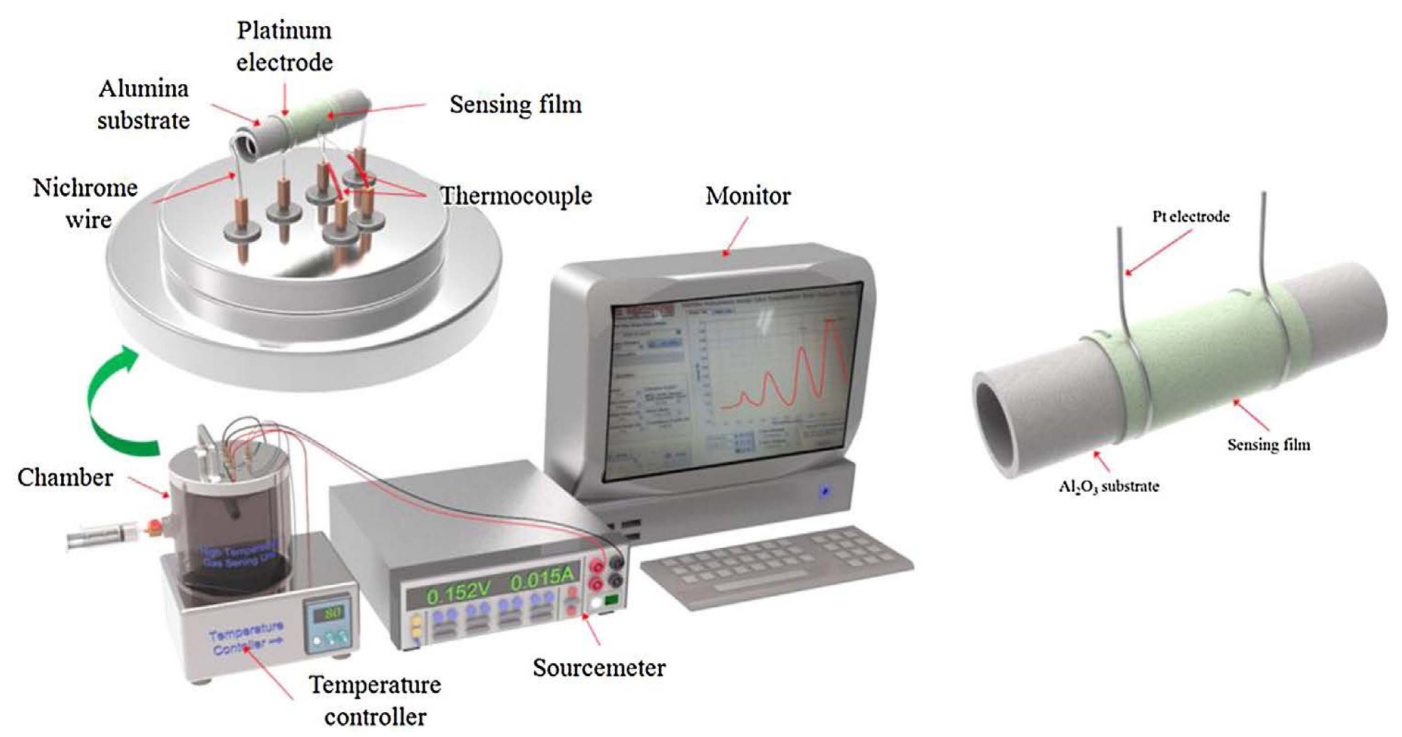

Fig. 2. Schematic of the experimental setup used for gas sensor evaluation. Reprinted with permission from reference.5) 

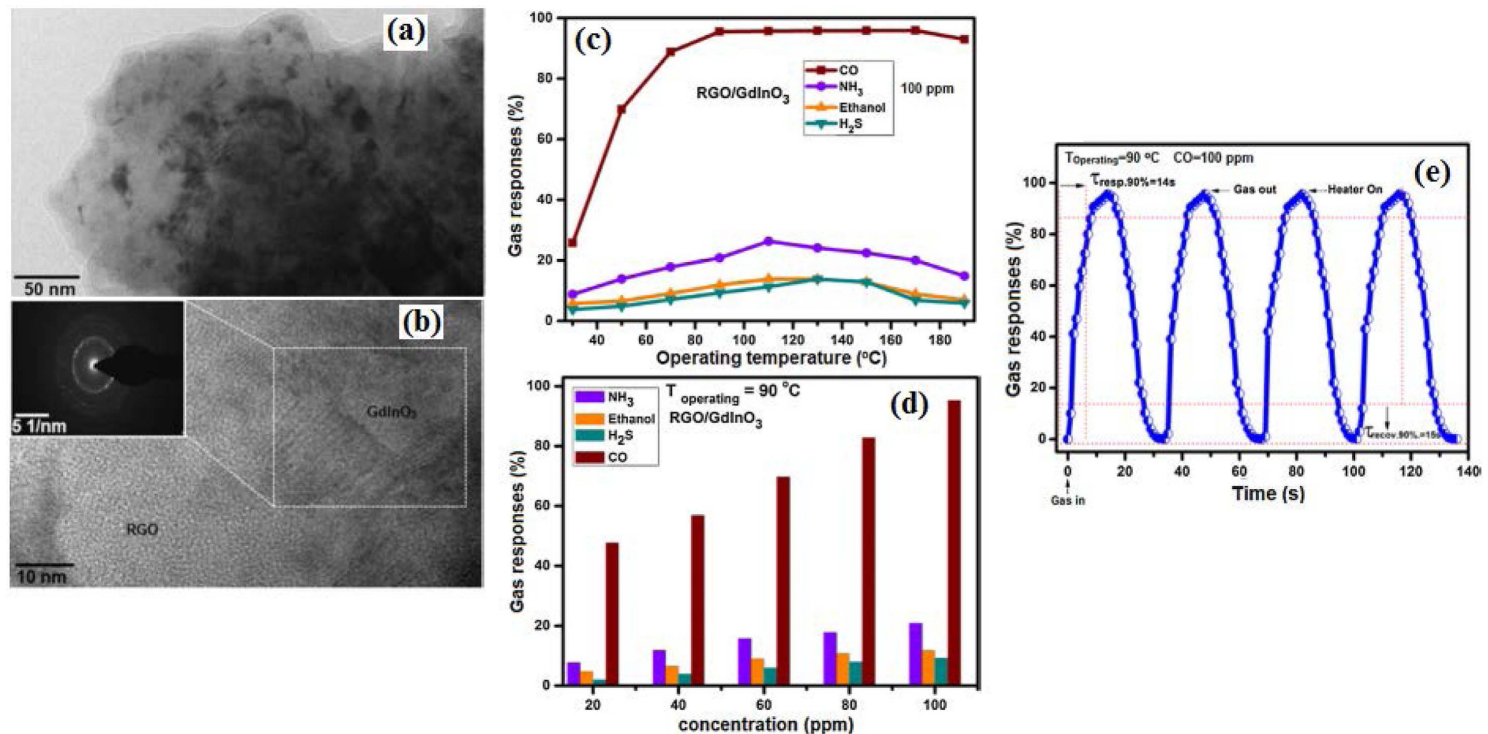

Fig. 3. Low and high TEM images of (a-b) the annealed $\mathrm{rGO} / \mathrm{GdInO}_{3}$ nanopowder, (e) $\mathrm{CO}$ response of the $\mathrm{rGO} / \mathrm{GdInO}_{3}$ as a function of operating temperature, (f) selectivity of the $\mathrm{GdInO}_{3}$ based gas sensors to different concentration of CO at optimum operating temperature (g) Response and recovery time of the $\mathrm{rGO} / \mathrm{GdInO}_{3}$. Reprinted with permission from reference. ${ }^{5)}$

using a single-step hydrothermal method for Co gas sensing applications and the sensor was fabricated by coated nanocomposites on alumina subtract. The $\mathrm{rGO} / \mathrm{GdInO}_{3}$ nanocomposites exhibited a significantly higher sensing response to CO than the bare $\mathrm{GdInO}_{3}$, and fast dynamic curves of response and recovery were obtained even at $90^{\circ} \mathrm{C}$ (Fig. 3), demonstrating that the $\mathrm{rGO} / \mathrm{GdInO}_{3}$ composite based sensor can detect low concentration $\mathrm{CO}$ rapidly at low temperatures. The enhanced sensing performance is mainly attributed to the catalytic effect of rGO to the oxidation of $\mathrm{CO}$ and strong interaction between the $\mathrm{rGO}$ and $\mathrm{GdInO}_{3}$ materials. Moreover, the vacancies or small holes created in the thermally reduced GO provide more active sites for much stronger $\mathrm{O}_{2}$ and $\mathrm{CO}$ adsorption than on the surface of the pure $\mathrm{GdInO}_{3}$ materials. ${ }^{5}$

\section{3. $\mathrm{YMnO}_{3}$ perovskite semiconductor gas sensor}

Recently, the research on perovskite-type oxides as possible gas sensors has been extensive, due to the high thermal stability, catalytic activity and semiconductor behavior of the oxides. ${ }^{32)}$ For example, $\mathrm{RMnO}_{3}(\mathrm{R}=\mathrm{Bi}, \mathrm{Y}, \mathrm{Gd}-\mathrm{Lu})$ has been studied as sensing materials. Many perovskite-related oxides show large variations in oxygen non-stoichiometry and defect concentrations, and they, therefore, have rich redox chemistries with variable oxidation states of the metal cations at the $\mathrm{B}$-sites in the $\mathrm{ABO}_{3}$ structure. ${ }^{33)}$ Furthermore, some structural features of perovskite-type oxides make them interesting material for investigation in gas sensors, electrodes for solid oxide fuel cells (SOFC), catalysts, and magnetic devices, among others. ${ }^{34)}$ Importantly, the $\mathrm{RMnO}_{3}(\mathrm{R}=$ yttrium and rare-earth materials) oxide forms in two structural phases. The hexagonal phase (space group $\mathrm{P} 63 \mathrm{~cm}, \mathrm{Z}=6$ ) forms with $\mathrm{R}=\mathrm{Ho}, \mathrm{Er}, \mathrm{Tm}, \mathrm{Yb}, \mathrm{Lu}$, or $\mathrm{Y}$, which have a small ionic radius, and the orthorhombic phase (space group Pnma, Z=4) for R=La, Ce, Pr, Nd, Sm, $\mathrm{Eu}, \mathrm{Gd}, \mathrm{Tb}$, or $\mathrm{Dy}$, which possesses a larger ionic radius. Orthohombic phase shows only ferromagnetic ordering while hexagonal phase shows both ferromagnetic and ferroelectric ordering. Recently, the hexagonal $\mathrm{YMnO}_{3}$ oxides are believed to be an excellent material, particularly for nonvolatile memory devices and MFS (Metal-FerroelectricsSemiconductor) devices because of their coupled magnetic and ferroelectric behavior. ${ }^{35)}$ Such electromagnetic multiferroics which exhibit simultaneous ferroelectricity and magnetism can be exploited in both electrical and magnetic applications. ${ }^{5,36-39)}$ Therefore, in our previous work, we have prepared hexagonal $\mathrm{YMnO}_{3}$ nanocrystalline powder via a novel citrate route. The hexagonal $\mathrm{YMnO}_{3}$ nanocrystalline powder shows excellent gas sensing characteristics towards $20 \mathrm{ppm} \mathrm{H}_{2} \mathrm{~S}$ gas at an operating temperature $100^{\circ} \mathrm{C}$ as shown in Fig. 4(a). The selectivity of hexagonal $\mathrm{YMnO}_{3}$ nanopowder based sensor was investigated by different reducing gases as a function of operating temperature and the concentrations of test gases. The sensor was exhibited high selectivity towards $20 \mathrm{ppm} \mathrm{H}_{2} \mathrm{~S}$ gas compared with those of the corresponding reducing gases $\mathrm{CO}, \mathrm{H}_{2}$, and LPG as shown in Fig. 4(b). The better sensing properties exhibited by $\mathrm{YMnO}_{3}$ could be attributed to their nanostructure with high a surface area, which can provide high reaction between $\mathrm{H}_{2} \mathrm{~S}$ gas and sensor material. Furthermore, the pores and nanostructure can act as a channel for the diffusion of gas and provide more active sites. Additionally, the presence of the higher order hexagonal phase can be an additional aspect responsible for high sensitivity of the $\mathrm{YMnO}_{3}$ material. Simultaneously, the $\mathrm{YMnO}_{3}$ system can produce more vacant oxygen, leading more oxygen species 

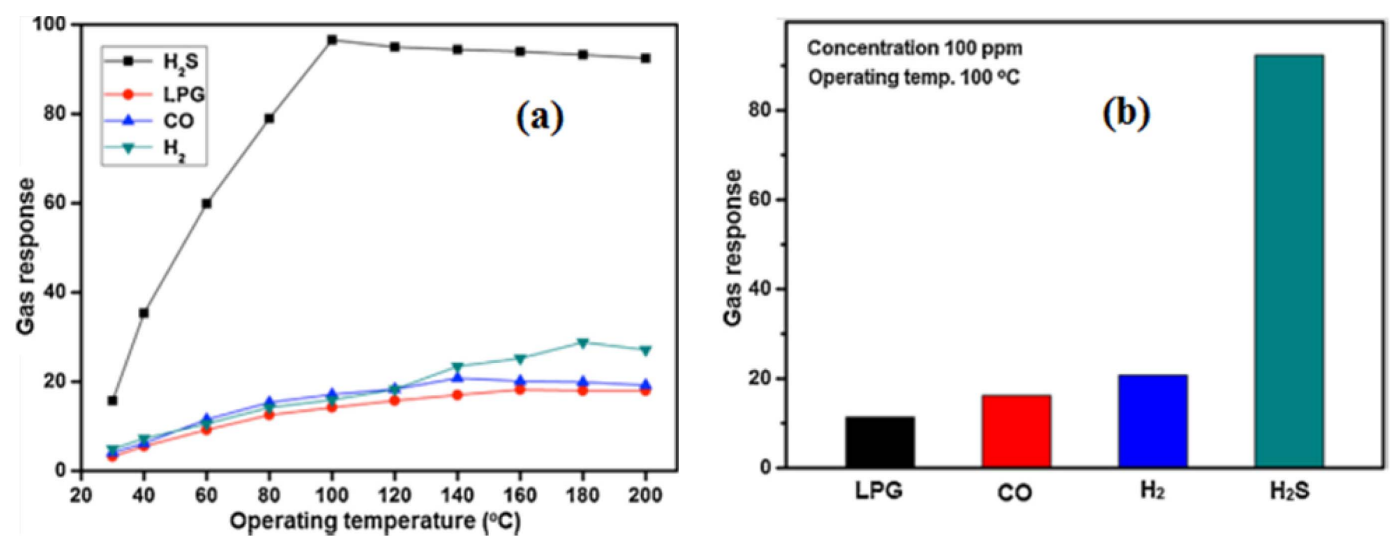

Fig. 4. (a) Sensor response toward $500 \mathrm{ppm}$ of reducing gases as a function of operating temperature. (b) Cross sensitivity of $\mathrm{YMnO}_{3}$ sensor element to the different gases at an operating temperature of $100^{\circ} \mathrm{C}$. Reprinted with permission from reference. ${ }^{3)}$

being absorbed on the surface of $\mathrm{YMnO}_{3}$, which eventually improves the oxidation of the exposed gas and getting shorter response time. Furthermore, manganese oxide can provide the basic surface for the $\mathrm{YMnO}_{3}$ sensor, allowing it to easily adsorb acidic $\mathrm{H}_{2} \mathrm{~S}$ gas, which may be the reason for its maximum response to $\mathrm{H}_{2} \mathrm{~S}$ with excellent selectivity. This system contains mixtures of metal oxide nanocrystals $\left(\mathrm{Y}^{+3} \mathrm{Mn}^{+3} \mathrm{O}_{3}^{-6}\right)$ that interact with each other and leads to a change in the electronic structure of the bulk nanocrystals and offer more advantage than single oxides for the sensi- tivity and selectivity detection of $\mathrm{H}_{2} \mathrm{~S}$ gas. ${ }^{3)}$

\section{4. $\mathrm{AB}_{2} \mathrm{O}_{6}$ and $\mathrm{ABO}_{4}$ Structured Materials for Gas Sensor}

\subsection{Cobalt niobates $\left(\mathrm{CoNb}_{2} \mathrm{O}_{6}\right)$ gas sensor}

The niobate or vanadium based $\mathrm{AB}_{2} \mathrm{O}_{6}$ compounds, $(\mathrm{A}=\mathrm{Ba}$, $\mathrm{Sr}, \mathrm{Mg}$ and $\mathrm{Zn}, \mathrm{B}=\mathrm{Nb}$ and $\mathrm{Ta}$ ) with either coulombite (orthorhombic) or trirutile (tetragonal) type structures show that they have excellent electrooptic, pyroelectric, magnetic,
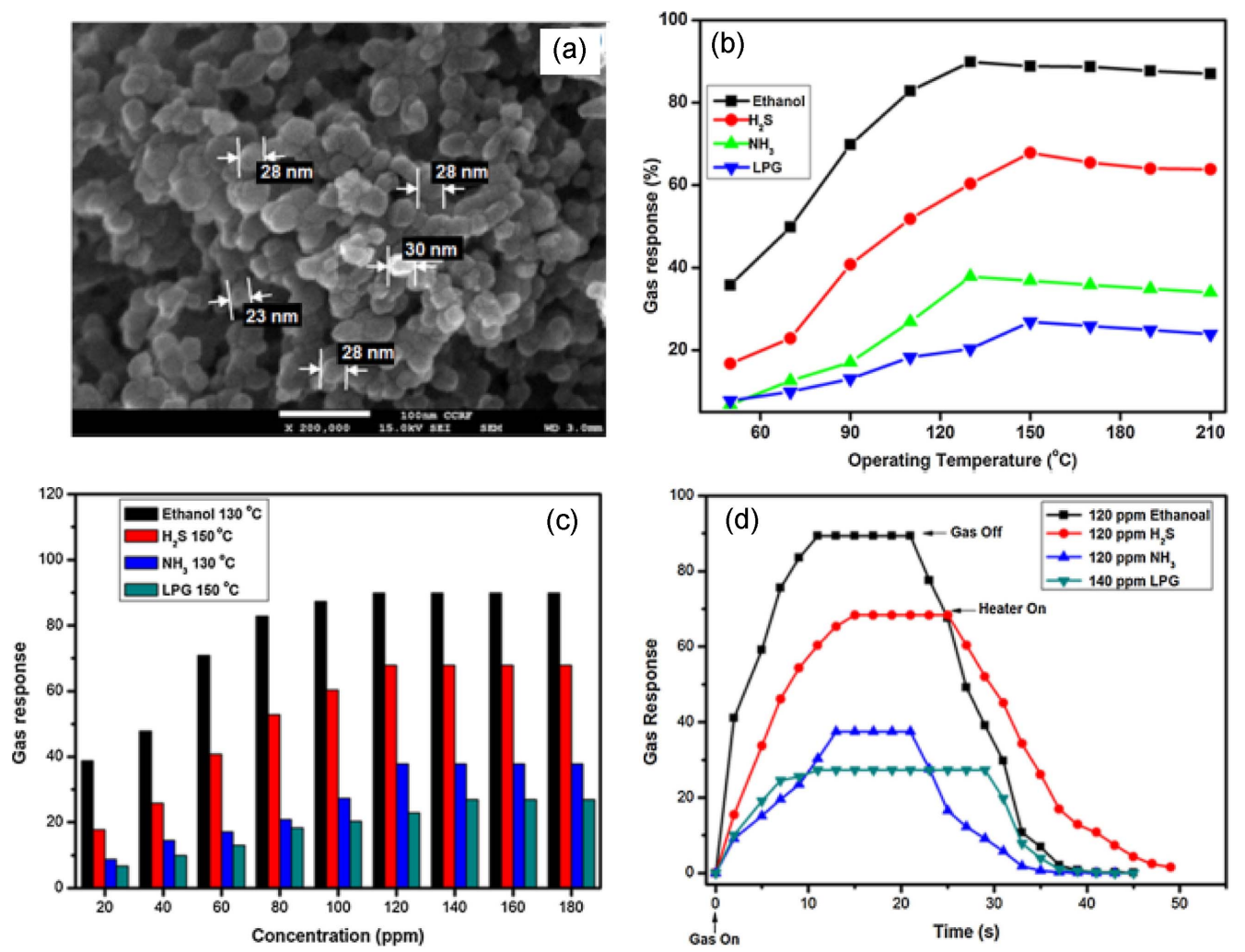

Fig. 5. (a) SEM image of $\mathrm{CoNb}_{2} \mathrm{O}_{6}$ nanopowder calcined at $700^{\circ} \mathrm{C}$. (b) The response of $\mathrm{CoNb}_{2} \mathrm{O}_{6}$ sensor as a function of various operating temperatures for $\mathrm{C}_{2} \mathrm{H}_{5} \mathrm{OH}, \mathrm{LPG}$, and $\mathrm{NH}_{3}$ gases. (c) selectivity of $\mathrm{CoNb}_{2} \mathrm{O}_{6}$ sensor as a function of ppm concentration at optimum operating temperatures for $\mathrm{C}_{2} \mathrm{H}_{5} \mathrm{OH}, \mathrm{H}_{2} \mathrm{~S}, \mathrm{LPG}$ and $\mathrm{NH}_{3}$ gases (d) response of $\mathrm{CoNb}_{2} \mathrm{O}_{6}$ sensor as a function of time at optimum operating temperatures. Reprinted with permission from reference. ${ }^{6}$ ) 
thermoelectric, piezoelectric, photo-refractive, and microwave dielectric applications..$^{40-43)}$ Recently, several combinations that can be accomplished through $\mathrm{A}$ and $\mathrm{B}$ yield a great variety of $\mathrm{AB}_{2} \mathrm{O}_{6}$ type composite oxides are promising sensing electrode alternatives due to their high thermal stability, excellent catalytic properties and ease of synthesis. It has been reported that the conventional ceramic route at high temperature is the common method of preparation of these compounds. Products obtained in this processes often have a wide particle size distribution and a wide particle size distribution. Nevertheless, other chemical routes have been explored, such as sol-gel method and wet-chemical method also require expensive niobates. Some reports of hydrothermal synthesis under mild conditions have been found, while most of the published studies were only concerned with the synthesis of alkali or alkaline-earthmetalniobates $\left(\mathrm{Na}^{+}, \mathrm{Mg}^{2+}, \mathrm{Ca}^{2+}\right.$, etc.). ${ }^{44-46}$ ) Transition metal niobates, especially the cobalt niobates ${ }^{47)}$ have attracted many scientists due to their fascinating and well-defined structure and intrinsic properties. The transition metal oxides depicting p-type nature and with $\mathrm{d}^{\mathrm{n}}$ (n varying between 1 and 9) configuration (i.e. oxides of $\mathrm{Cr}$, $\mathrm{Co}, \mathrm{Fe}$, etc.) are easily susceptible to oxidation as well as reduction. ${ }^{48)}$ Further, the high mobility of oxygen and stabilization of unusual oxidation states in their structure are believed to successfully employ for gas sensing application. However, some researchers have reported the magnetic properties of $\mathrm{CoNb}_{2} \mathrm{O}_{6}$, but a sensing application on this material has not been reported. The first time we reported synthesis and characterization of $\mathrm{CoNb}_{2} \mathrm{O}_{6}$ nanopowder and investigated their ethanol vapor sensing performance. ${ }^{6)}$ The sensitivity of the $\mathrm{CoNb}_{2} \mathrm{O}_{6}$ based sensor was studied by measuring the resistance of the sensor in the air and the reducing gas envi- ronments such as $\mathrm{C}_{2} \mathrm{H}_{5} \mathrm{OH}, \mathrm{H}_{2} \mathrm{~S}, \mathrm{NH}_{3}$, and LPG. Fig. 5(a) shows the SEM image of the prepared $\mathrm{CoNb}_{2} \mathrm{O}_{6}$ nanopowder. The gas response characteristics of Fig. 5(b-d) clearly show that this $\mathrm{CoNb}_{2} \mathrm{O}_{6}$ based sensor is higher response to ethanol gas at $130^{\circ} \mathrm{C}$, the $120 \mathrm{ppm}$ ethanol response increased sharply to reach $89 \%$ of its saturated level height within $10 \mathrm{~s}$. The selectivity plot of $\mathrm{CoNb}_{2} \mathrm{O}_{6}$ at an optimum operating temperature at different concentrations of interfering gases clearly shows that this sensor is highly selective for ethanol gases. The $120 \mathrm{ppm}$ ethanol response time was about $10 \mathrm{~s}$ and the recovery time was about $18 \mathrm{~s}$. Similarly, for other gases such as $\mathrm{H}_{2} \mathrm{~S}$, the response time and recovery were 14 and $25 \mathrm{~s}$, respectively, for $\mathrm{NH}_{3}$ they were 13 and $15 \mathrm{~s}$, respectively, and for LPG they were 10 and 10 $\mathrm{s}$, respectively. From above the result, we concluded that the $\mathrm{CoNb}_{2} \mathrm{O}_{6}$ sensor might be a preferable candidate for detecting ethanol.

\section{2. $\mathrm{NH}_{3}$ gas sensor based on vanadium-based mate-} rial

Various sensing materials such as transition metal compounds and conducting polymers have been extensively studied for $\mathrm{NH}_{3}$ gas sensor applications, among which vanadium oxide based material results from a number of different interrelated electronic and structural factors. These compounds have partially filled d-orbitals which are responsible for a wide variety of electronic, magnetic and catalytic properties. $^{49)}$ The phase diagram shows that vanadium atoms exist in different formal oxidation states, which vary from two to five. The easy conversion between oxides of different stoichiometry and formation of oxygen vacancies enables the oxide to function as a catalyst for selective oxidation. ${ }^{50)}$ For gas-sensing applications, a vanadium-based
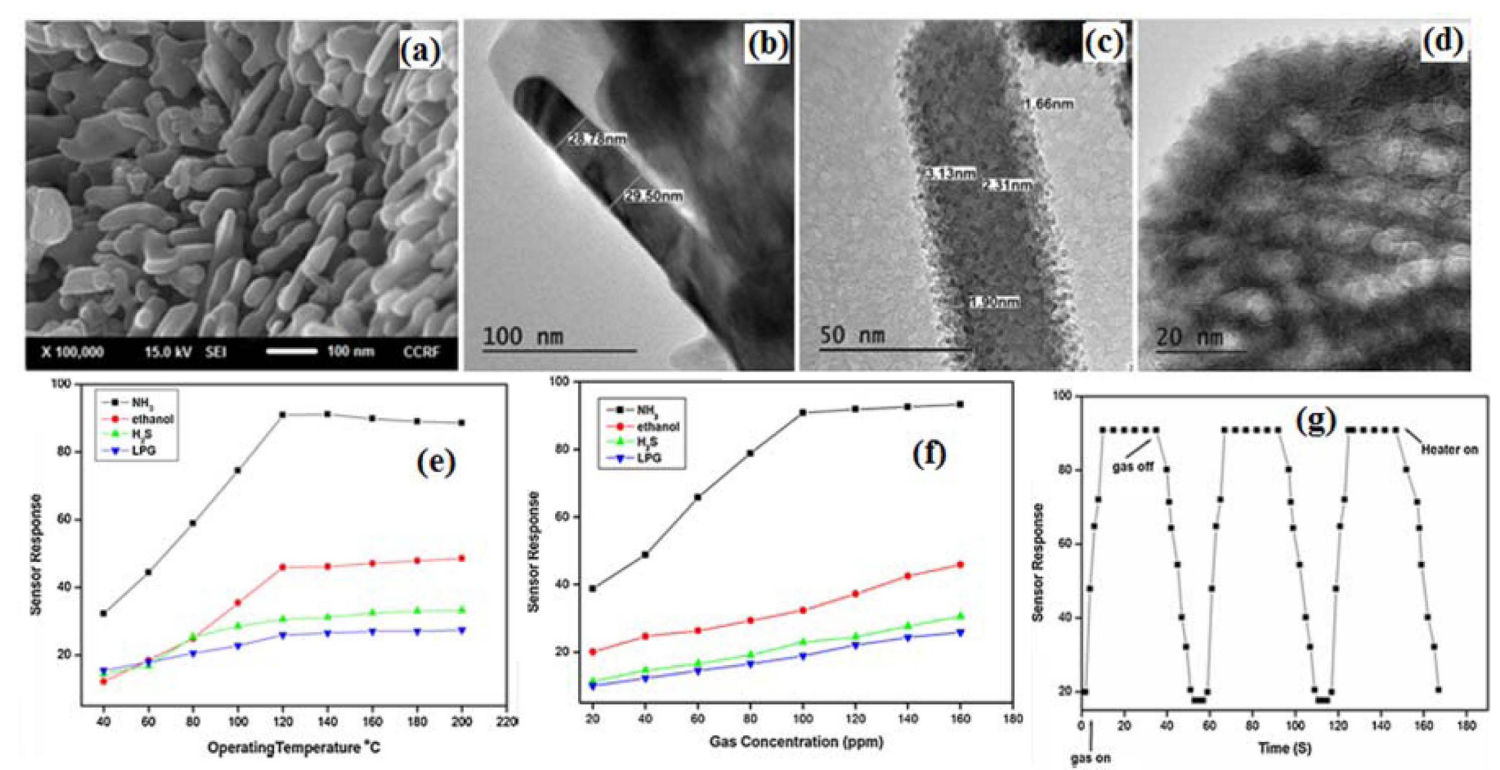

Fig. 6. (a) $\mathrm{SEM}$ image of $\mathrm{NiV}_{2} \mathrm{O}_{6}$ nanopowder, (b-d) HR-TEM image of rod-like $\mathrm{NiV}_{2} \mathrm{O}_{6}$ nanostructures (e) response of a sensor to reducing gases as a function of operating temperature, (f) response of the sensor to different concentrations of $\mathrm{NH}_{3}$, ethanol, $\mathrm{H}_{2} \mathrm{~S}$, and $\mathrm{LPG}$ at $120^{\circ} \mathrm{C}$, (g) response and recovery time of the sensor to $100 \mathrm{ppm} \mathrm{NH}_{3}$ at $120^{\circ} \mathrm{C}$. Reprinted with permission from reference. ${ }^{13)}$ 
material is a promising choice due to its high catalytic application, environmentally benign nature and low cost. ${ }^{13)}$ Therefore we reported first time mesoporous $\mathrm{NiV}_{2} \mathrm{O}_{6}$ nanopowder for an $\mathrm{NH}_{3}$ gas sensing application. Among the various synthesis methods, author prepared $\mathrm{NiV}_{2} \mathrm{O}_{6}$ nanopowder using a simple and reliable solution based method.

Figure 6(a-d) shows the prepared $\mathrm{NiV}_{2} \mathrm{O}_{6}$ nanopowder SEM and TEM images. Fig. 6(e-g) in reference ${ }^{13)}$ indicated that the sensor sample based on $\mathrm{NiV}_{2} \mathrm{O}_{6}$ nanostructure produced by solution based method had higher response and shorter response time to $100 \mathrm{ppm}$ ammonia at $120^{\circ} \mathrm{C}$. This material can have bivalent catalytic centers by assuming that charge transport might occur via the $\mathrm{Ni}^{+}-\mathrm{O}-\mathrm{Ni}^{2+}$ framework with all $\mathrm{V}$ ions in a +5 state or $\mathrm{V}^{4+}-\mathrm{O}-\mathrm{V}^{5+}$ framework with all $\mathrm{Ni}$ ions in a +2 state. Moreover, higher sensing activity of $\mathrm{NiV}_{2} \mathrm{O}_{6}$ nanopowder may be attributed to the fact that besides the one component sites $\mathrm{Ni}^{1+}-\mathrm{O}-\mathrm{Ni}^{2+}$ and $\mathrm{V}^{5+}-\mathrm{O}-$ $\mathrm{V}^{4+}$, there will be also the mixed sites $\mathrm{Ni}^{1+}-\mathrm{O}-\mathrm{V}^{5+}$ and/or $\mathrm{Ni}^{2+}$ $\mathrm{O}-\mathrm{V}^{4+}$ ion pairs as a result of mutual charge interaction. Therefore, the presence of fraction of reduced $\mathrm{V}^{4+}$ ions in the system is capable to reduce $\mathrm{Ni}^{2+}$ major centres partly to ions of lower oxidation, whereas $\mathrm{Ni}^{1+}$ minor centres being more active species in $\mathrm{NH}_{3}$ sensing reaction. Here the presence of vanadium atom seems to stabilize the catalyst structure against oxidation as well as reduction and to permit a very strongly oxidized/reduced sensing material. This leads to easy recovery of the original state of the sensing material.
This means that the observed changes of the electrical resistance are probably due to the changes of valence state of catalytically active components of the sensor material. ${ }^{13)}$

\section{3. $\mathrm{ABO}_{4}$ structured materials for gas sensor}

$\mathrm{ABO}_{4}$ compounds $\left(\mathrm{A}=\right.$ transitions metal and $\mathrm{B}=\mathrm{Nb}^{5+}, \mathrm{Ta}^{5+}$ or $\mathrm{Sb}^{5+}$ ) have received much attention owing to their unique properties such as ferroelectrics and anti-ferroelectrics with the stibiotantalite structure which consists of layer of vertex sharing, distorted $\mathrm{BO}_{6}$ octahedral parallel to the (001) plane of the orthorhombic unit cell. Moreover, they possess excellent piezoelectric, pyroelectric and electro-optic properties at room temperature. ${ }^{51)}$ Very recently; our group reported a series of porous $\mathrm{ABO}_{4}$ structure-based nanoparticles that were synthesized for use in $\mathrm{NH}_{3}$, ethanol, and LPG gas sensing applications.

\section{4. $\mathrm{NH}_{3}$ gas sensor based on $\mathrm{ABO}_{4}$ bismuth material}

Among the various $\mathrm{ABO}_{4}$ compound, bismuth-based microwave dielectric ceramic has stimulated great research interest owing to its unique structural, electrical properties and promising applications in the field of multilayer capacitor. ${ }^{52-54)}$ From the viewpoint of gas sensors, $\mathrm{BiNbO}_{4}$ could be considered as promising candidate for future developments of sensing materials. According to the sensing mechanisms of gas sensors, the overall sensor conductance is determined by surface reactions and the charge transfer processes
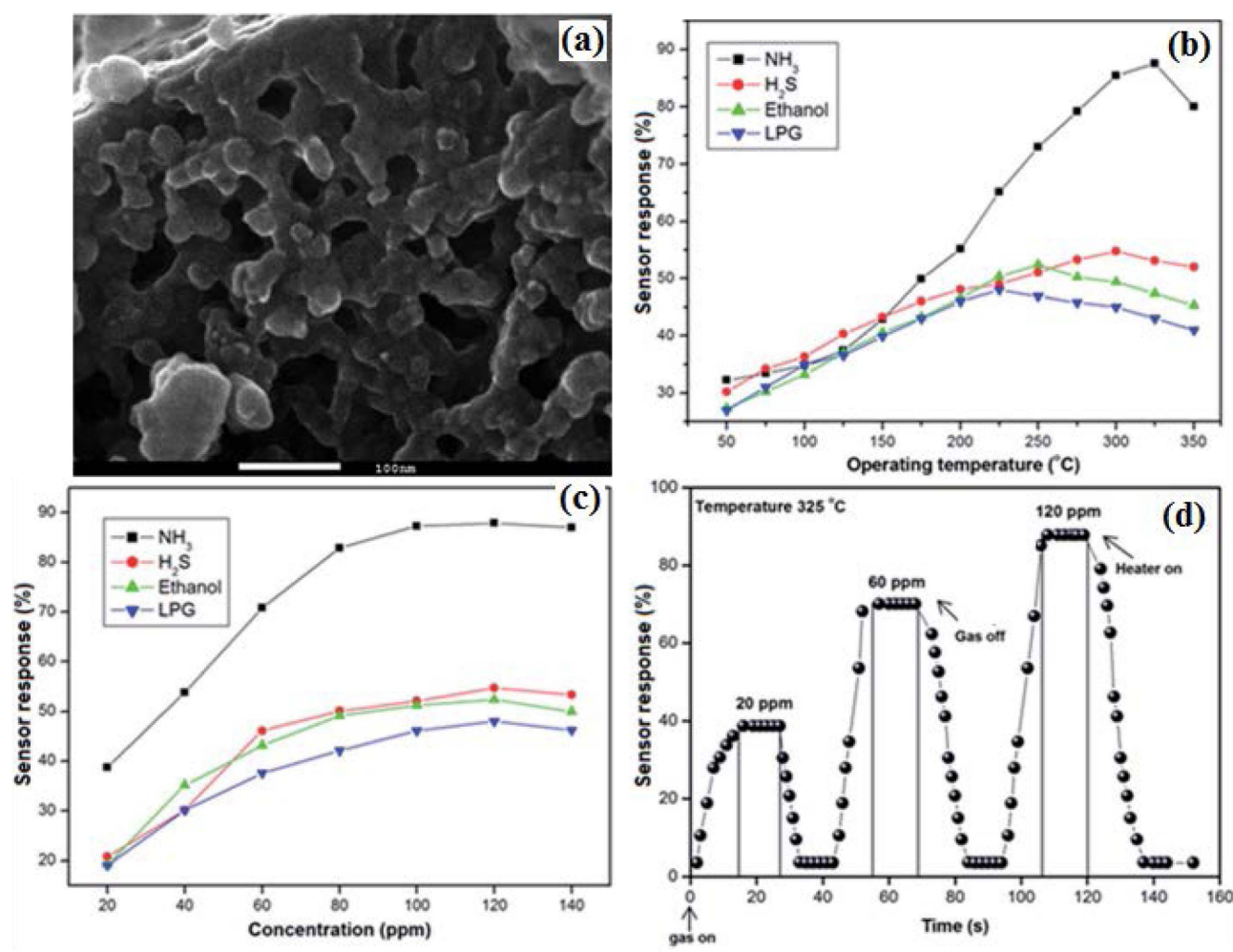

Fig. 7. (a) FE-SEM images of $\mathrm{BiNbO}_{4}$, (b) dynamic gas sensing characteristics of $\mathrm{BiNbO}_{4}$ nanopowder towards $\mathrm{NH}_{3}, \mathrm{H}_{2} \mathrm{~S}$, ethanol, and LPG as a function of operating temperatures, (c) gas sensing response of $\mathrm{BiNbO}_{4}$ as a function of concentrations $(20-140 \mathrm{ppm})$ and (d) response and recovery time of the sensor to different concentrations of $\mathrm{NH}_{3}$. Reprinted with permission from reference. ${ }^{7}$ 
between the adsorbed species and the sensing material. ${ }^{55)}$ With the progress of gas sensing research, it has been found that porous structure with a high specific surface area and surface accessibility can significantly improve the gas sensing properties. Therefore, we reported the $\mathrm{NH}_{3}$ sensing behavior of the novel $\mathrm{BiNbO}_{4}$ nanopowder. ${ }^{7}$ ) The obtained $\mathrm{BiNbO}_{4}$ nanopowder SEM morphology is shown in Fig. 7(a). The sensing response of $\mathrm{BiNbO}_{4}$ based material was studied by varying its electrical resistance in the air and reducing gas environments. The $\mathrm{BiNbO}_{4}$ nanopowder-based sensor detects $\mathrm{NH}_{3}$ selectively over other interfering gases such as $\mathrm{H}_{2} \mathrm{~S}$, ethanol and $\mathrm{LPG}$.

In order to obtain the optimum operating temperature $\left(\mathrm{T}_{\text {opt }}\right)$ for $\mathrm{NH}_{3}$, the sensor response was analyzed over a temperature range of $50-350^{\circ} \mathrm{C}$ keeping the gas concentration constant. The $\mathrm{T}_{\text {opt }}$ for $\mathrm{NH}_{3}$ sensing was found at the temperature of about $325^{\circ} \mathrm{C}$. The chances of cross-sensitivity during $\mathrm{NH}_{3}$ sensing at $\left(\mathrm{T}_{\mathrm{opt}}\right)$ is clarified by obtaining $\mathrm{T}_{\text {opt }}$ for the test gases such as hydrogen sulphide $\left(\mathrm{H}_{2} \mathrm{~S}\right)$, ethanol $\left(\mathrm{C}_{2} \mathrm{H}_{5} \mathrm{OH}\right)$ and liquid petroleum gas (LPG). The $\mathrm{T}_{\text {opt }}$ for $\mathrm{H}_{2} \mathrm{~S}$ (54\%), ethanol (46\%) and LPG (40\%) sensing is found to be 300,250 and $225^{\circ} \mathrm{C}$, respectively (Fig. 7(b)). The gas sensing response of $\mathrm{BiNbO}_{4}$ as a function of various concentrations of test gases at their $\mathrm{T}_{\text {opt }}\left(\mathrm{NH}_{3}-325^{\circ} \mathrm{C}, \mathrm{H}_{2} \mathrm{~S}-305^{\circ} \mathrm{C}\right.$, ethanol$250^{\circ} \mathrm{C}, \mathrm{LPG}-225^{\circ} \mathrm{C}$ ) is shown in Fig. 7 (c). The sensor response is remarkably high when exposed $\mathrm{NH}_{3}$ at its $\mathrm{T}_{\text {opt }}$ compared the sensing response of other gases at their respective $\mathrm{T}_{\mathrm{opt}}$. While the sensor response is low when exposed to comparable concentration of interfering gases such as $\mathrm{H}_{2} \mathrm{~S}$, ethanol and LPG, this indicates clearly a selective response of the sensor towards ammonia. This selective response was owing to the complete oxidization of $\mathrm{NH}_{3}$ on the sensor surface, thereby changing the conductivity of the sensor element drastically compared to other gases. The measured response for $20 \mathrm{ppm}, 60 \mathrm{ppm}$, and $120 \mathrm{ppm} \mathrm{NH}_{3}$ gas is around 38\%, $70 \%$ and $87 \%$, respectively. It can be seen that $\mathrm{NH}_{3}$ gas attained maximum response within $16 \mathrm{~s}$ and their recovery time was less than $17 \mathrm{~s}$ (Fig. 7(d)). The fast response, as well as recovery of the above discussed sensor, can be attributed to the large surface area and high porosity of the prepared sensor material. The improved selectivity obtained with this $\mathrm{BiNbO}_{4}$ sensor makes it a valuable tool in the determination of $\mathrm{NH}_{3}$ gas.

\subsection{LPG gas sensor based on $\mathrm{LaNbO}_{4}$ material}

$\mathrm{LaNbO}_{4}$ is an excellent ceramic oxide having high thermal and mechanical stability. It exhibits polymorphism viz. monoclinic and tetragonal phases. ${ }^{56)} \mathrm{LaNbO}_{4}$ is used in solid oxide fuel cells, hydrogen sensors etc., because of its enhanced physical and chemical properties. ${ }^{57-59)}$ In the field of gas-sensing materials, $\mathrm{LaNbO}_{4}$ could be considered as a potential candidate for future developments of sensing materials. Therefore, we reported the first time for LPG, $\mathrm{NH}_{3}$ and ethanol sensing properties of nanocrystalline LaN$\mathrm{bO}_{4}$ prepared by the solution-based method. ${ }^{60)}$ The gas response characteristics of the $\mathrm{LaNbO}_{4}$ based sensor has been studied by measuring the resistance of the sensor material in air and then in a reducing gas environment. Fig. 8(a) and (b) show the schematic of sensor element and electrical circuit of the $\mathrm{LaNbO}_{4}$ gas response studies. (b) Fig. 9(a and $b$ ) shows the SEM and TEM morphology of prepared $\mathrm{LaNbO}_{4}$ nanocrystalline. Fig. 9(c) shows the gas sensitivity versus operating temperature for $\mathrm{LaNbO}_{4}$ based sensor for different test gases. At $250^{\circ} \mathrm{C}$, the highest gas sensitivity for LPG was $80 \%$, while other gases gave $59 \%$ for ammonia and $22 \%$ for ethanol gas at $250^{\circ} \mathrm{C}$. When exposed to reducing gases like liquid petroleum gas (LPG) ammonia $\left(\mathrm{NH}_{3}\right)$ and ethanol $\left(\mathrm{C}_{2} \mathrm{H}_{5} \mathrm{OH}\right)$ Compared to ammonia and ethanol, LaN$\mathrm{bO}_{4}$ showed the highest response for LPG at an operating temperature of $250^{\circ} \mathrm{C}$. This may be attributed to the availability of sufficient adsorbed ionic species of oxygen on the sensor surface which reacts most efficiently with LPG molecules at this particular temperature. Beyond the optimum temperature, desorption of all oxygen ionic species occurs causing a decrease in sensitivity. The temperature plays an important role in the charge carrier concentration and the

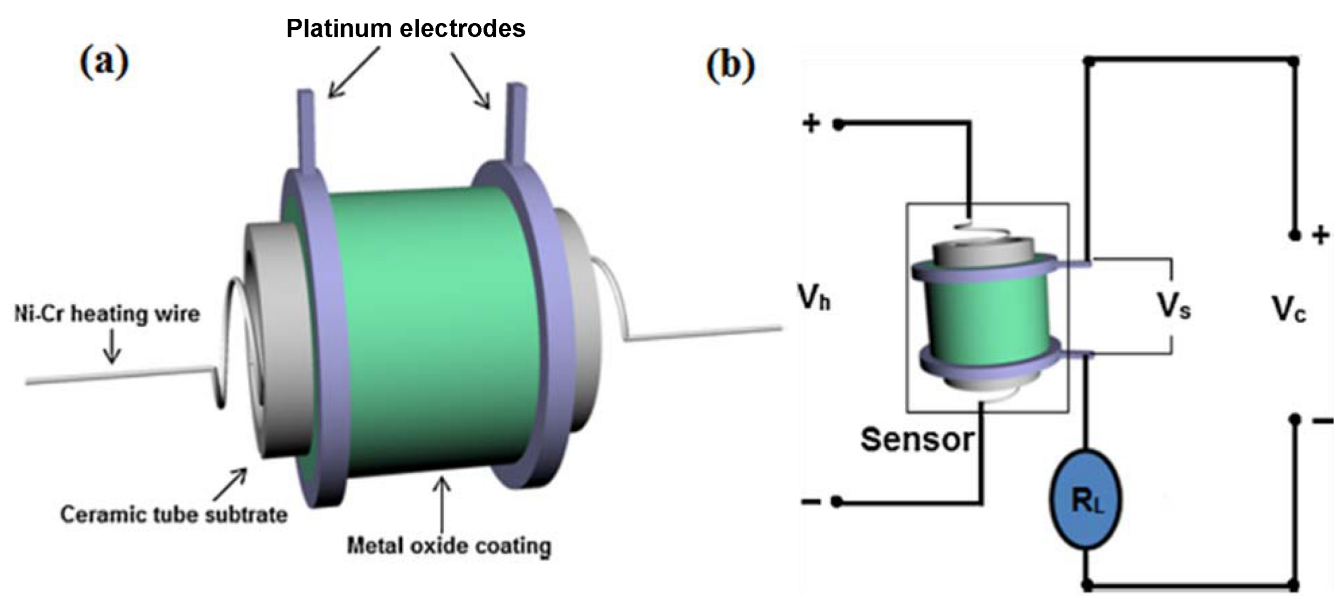

Fig. 8. (a) The schematic of sensor element used for the gas response studies (b) electrical circuit of the gas response test system (Vh: heating voltage, Vc: circuit voltage, Vc: output signal voltage and RL: load resistance). Reprinted with permission from reference. ${ }^{60)}$ 

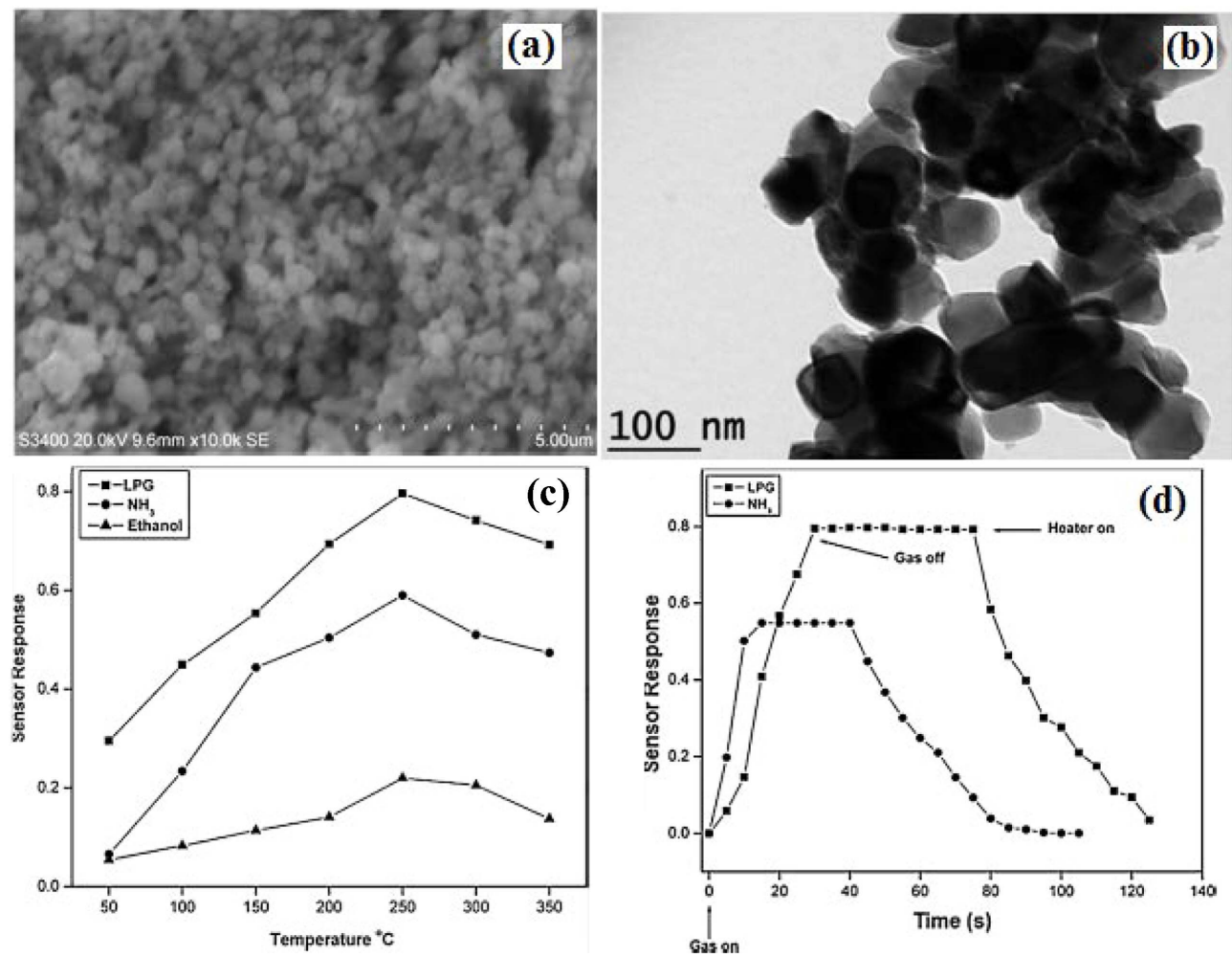

Fig. 9. (a-b) SEM and TEM image of the $\mathrm{LaNbO}_{4}$ nanopowder calcined at $900^{\circ} \mathrm{C}$ (c) variation in gas response for $\mathrm{LPG}, \mathrm{NH}_{3}$ and ethanol gas as a function of gas concentrations at $250^{\circ} \mathrm{C}$ (d) response and recovery of $\mathrm{LaNbO}_{4}$ sensor as a function of time at their optimum operating temperatures for $\mathrm{LPG}$ and $\mathrm{NH}_{3}$ gases. Reprinted with permission from reference. ${ }^{60)}$

Debye length. This may be one of the reasons for the decrease in sensitivity of the $\mathrm{LaNbO}_{4}$ sensor at higher temperature. Fig. 9(d). depicts the response and recovery curves to 500 ppm LPG and $\mathrm{NH}_{3}$ gas of $\mathrm{LaNbO}_{4}$ sensor at an operating temperature $250^{\circ} \mathrm{C}$. When LPG gas was introduced, the response time of sensor to reach the maximum response was less than $25 \mathrm{~s}$ and the recovery time to restore original value from the maximum response was less than $100 \mathrm{~s}$. The response and recovery time for $\mathrm{NH}_{3}$ it was $10 \mathrm{~s}$ and $80 \mathrm{~s}$, respectively. $\mathrm{LaNbO}_{4}$ based sensor has very promising future for LPG detection in the low ppm range with a response time in the seconds range.

\subsection{Ethanol gas sensor based on InNbO $\mathrm{O}_{4}$ material}

$\mathrm{InNbO}_{4}$ based semiconductor materials have been attracted by many researchers due to its unique structural and important physical properties. ${ }^{61-63)}$ This can also be used as a key precursor for the ferroelectric perovskite, lead indium niobate, $\mathrm{Pb}\left(\mathrm{In}_{1 / 2} \mathrm{Nb}_{1 / 2}\right) \mathrm{O}_{3}$, for actuator, transducer and ultrasonic motor applications. ${ }^{64)}$ Indium niobate based materials were prepared by solid-state reactions of $\operatorname{In}_{2} \mathrm{O}_{3}$ and $\mathrm{Nb}_{2} \mathrm{O}_{5}$ at high calcination temperatures. However, this preparation process had several disadvantages such as controlling the component homogeneity, crystal size, stoichiometric ratio, and formation of un-desirable phases. Therefore, we prepared monoclinic $\mathrm{InNbO}_{4}$ nanopowder using a low temperature niobium citrate complex process. ${ }^{65)}$ This process yielded reactive powder with high purity, higher surface areas, fine particle size, high degree of crystallinity, and low temperature sinterability, compared to the powder prepared by conventional solid state reaction method. In addition, as the reactants are mixed in an aqueous solution, this method enabled to produce a good chemical homogeneity of the system. The gas sensing properties of the $\mathrm{InNbO}_{4}$ nanopowder had been studied for different gases such as liquid petroleum gas (LPG), ammonia $\left(\mathrm{NH}_{3}\right)$ and ethanol $\left(\mathrm{C}_{2} \mathrm{H}_{5} \mathrm{OH}\right)$ at various operating temperatures. The response of $\mathrm{InNbO}_{4}$ nanopowder as a function of gas concentrations as well as with recovery time had also been studied. The $\mathrm{InNbO}_{4}$ sensor showed highest sensitivity for LPG (0.97) and $\mathrm{NH}_{3}(0.70)$ gas at $300^{\circ} \mathrm{C}$ and for ethanol $(0.46)$ at $325^{\circ} \mathrm{C}$ as shown in Fig. 10(b). Fig. 10(c) revealed the sensor response of $\mathrm{InNbO}_{4}$ as a function of various concentrations of test gases at their optimal operating temperatures. The sensor response increased with increase in concentrations of test gases and attained almost a maximum response at $500 \mathrm{ppm}$ for all three gases. Fig. 10(d) showed the sensor response with time for LPG, $\mathrm{NH}_{3}$ and ethanol gas at the optimum operating temperature of $300^{\circ} \mathrm{C}$ for $\mathrm{LPG}, \mathrm{NH}_{3}$ and $325^{\circ} \mathrm{C}$ for ethanol, respectively. It can be seen that LPG gas attained maximum response within 14 second and it was 35 second for ethanol and 19 second for ethanol, respectively. However, their recovery times were less than $124 \mathrm{~s}, 114 \mathrm{~s}$ and $99 \mathrm{~s}$, for LPG, $\mathrm{NH}_{3}$ and ethanol gases, respectively. 

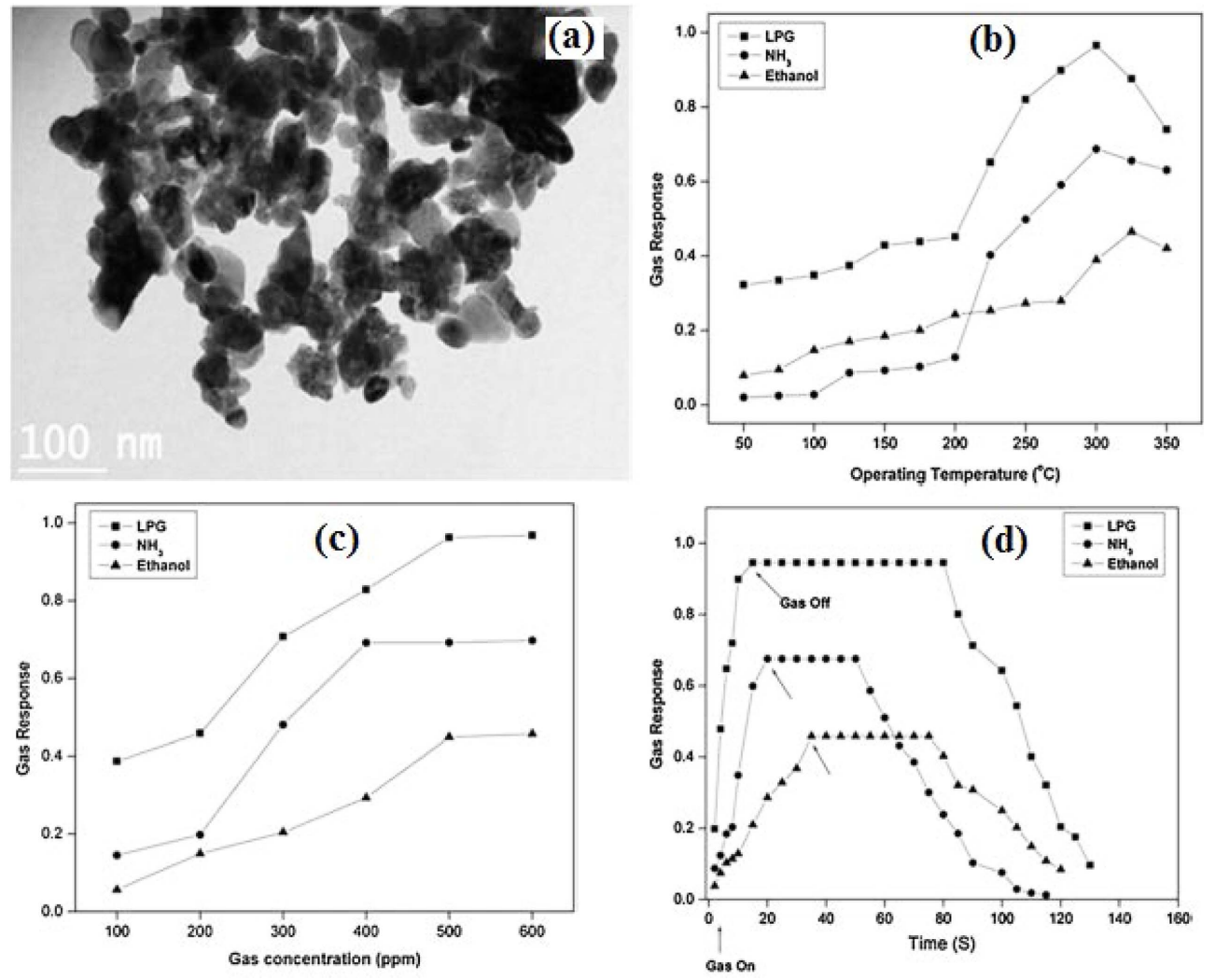

Fig. 10. (a) TEM image of $\mathrm{InNbO}_{4}$ obtained at $600^{\circ} \mathrm{C}$. (b) gas sensing characteristics of $\mathrm{InNbO}_{4}$ sensor as a function of various operating temperatures for $\mathrm{LPG}, \mathrm{NH}_{3}$ and $\mathrm{C}_{2} \mathrm{H}_{5} \mathrm{OH}$ gases. (c) sensitivity of $\mathrm{InNbO}_{4}$ sensor with the different concentrations of LPG, $\mathrm{NH}_{3}$ and $\mathrm{C}_{2} \mathrm{H}_{5} \mathrm{OH}$ at their optimum operating temperatures. (d) response of $\mathrm{InNbO}_{4}$ sensor as a function of time at their optimum operating temperatures for $\mathrm{LPG}, \mathrm{NH}_{3}$ and $\mathrm{C}_{2} \mathrm{H}_{5} \mathrm{OH}$ gases. Reprinted with permission from reference. ${ }^{65}$

\subsection{LPG gas sensor based on $\mathrm{CrNbO}_{4}$ material}

$\mathrm{CrNbO}_{4}$ is one of the well known compounds of the $\mathrm{ABO}_{4}$ family which has recently gained considerable attention, because of its interesting physical and chemical properties such as polymorph, magnetic and electrochemical properties due to its ionic and electronic defects. In addition, the phase relationship and dielectric properties indicated that to possess sensing activity. In general, this compound is synthesized by the conventional ceramic route, in which appropriate amount of metal oxide are mixed, and then the mixture is heated for a long period at high temperatures. This preparation process has led to uncontrollable grain growth and non-stoichiometry problem due to volatilization of the constituent components at high temperature, which results in a decrease in the gas sensitivity of the obtained material to a great extent. Therefore, it is necessary to develop nanosized $\mathrm{CrNbO}_{4}$ for gas sensor applications. We reported the synthesis of $\mathrm{CrNbO}_{4}$ nanopowder by niobiumcitrate complex process. ${ }^{66)}$ The TEM result in Fig. 11(a) showed the average particle size of $\mathrm{CrNbO}_{4}$ is $25 \mathrm{~nm}$. The gas sensing properties of $\mathrm{CrNbO}_{4}$ nanopowder to three typical reducing gases were tested (Fig. 11(b) - (d)). The results indicated that the sensors had high responses to LPG and ethanol at $325^{\circ} \mathrm{C}$ and $300^{\circ} \mathrm{C}$, respectively. The response time of LPG, ethanol and NH3 were about 9, 19, $35 \mathrm{~s}$, respectively.

\section{8. $\mathrm{AlNbO}_{4}$ material based gas sensor}

Due to its enhanced sensitivity, the development of semiconductor metal oxide sensors is of continued interest. Niobium based binary metal oxides such as $\mathrm{AlNbO}_{4}$ is being studied extensively, exhibit interesting structural, chemical electrical and optical properties. Therefore, in the previous investigation, we report the synthesis of $\mathrm{AlNbO}_{4}$ nanopowder by niobium-citrate complex process. ${ }^{67)}$ The gas response properties of prepared $\mathrm{AlNbO}_{4}$ nanopowder based sensor were studied by measuring the resistance of the sensor in air and in the reducing gas environment. SEM and TEM microstructure of $\mathrm{AlNbO}_{4}$ in Fig. 12(a-b) shows the porous nature of the surface and the average size of the rectangle shaped nanoparticles was $30 \mathrm{~nm}$ in width and $60 \mathrm{~nm}$ in length, respectively. The gas sensing properties of $\mathrm{AlNbO}_{4}$ based sensor was examined at the temperatures in the range of $50-350^{\circ} \mathrm{C}$ as shown in Fig. $12(\mathrm{c})$. $\mathrm{AlNbO}_{4}$ nanopowder had n-type behaviour and good response towards ethanol compared to the other two reducing gases (LPG and $\mathrm{NH}_{3}$ ) at an operating temperature of $250^{\circ} \mathrm{C}$. This sensor is very promising for selective ethanol detection in the low 

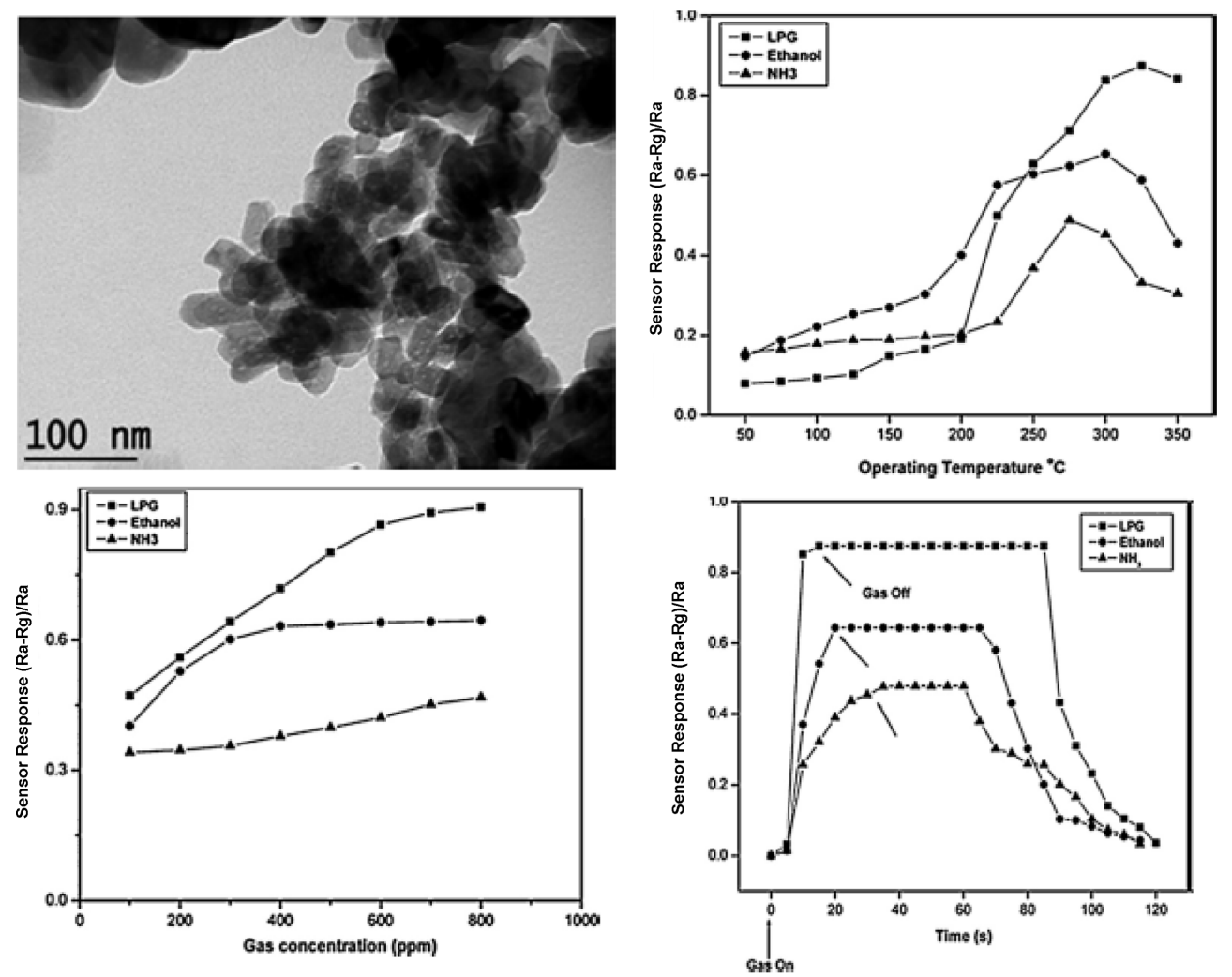

Fig. 11. (a) TEM micrograph of $\mathrm{CrNbO}_{4}$ powder obtained at $800^{\circ} \mathrm{C}$. (b) response of $\mathrm{CrNbO}_{4}$ sensor in $\mathrm{LPG}$, ethanol and $\mathrm{NH}$ gases as a function of operating temperatures. (c) response of $\mathrm{CrNbO}_{4}$ sensor with different concentrations of LPG, ethanol and $\mathrm{NH}_{3}$ at their optimum operating temperature. (d) response of $\mathrm{CrNbO}_{4}$ sensor as a function of time at their optimum operating temperatures for $\mathrm{LPG}$, ethanol and $\mathrm{NH}_{3}$ gases. Reprinted with permission from reference. ${ }^{66)}$
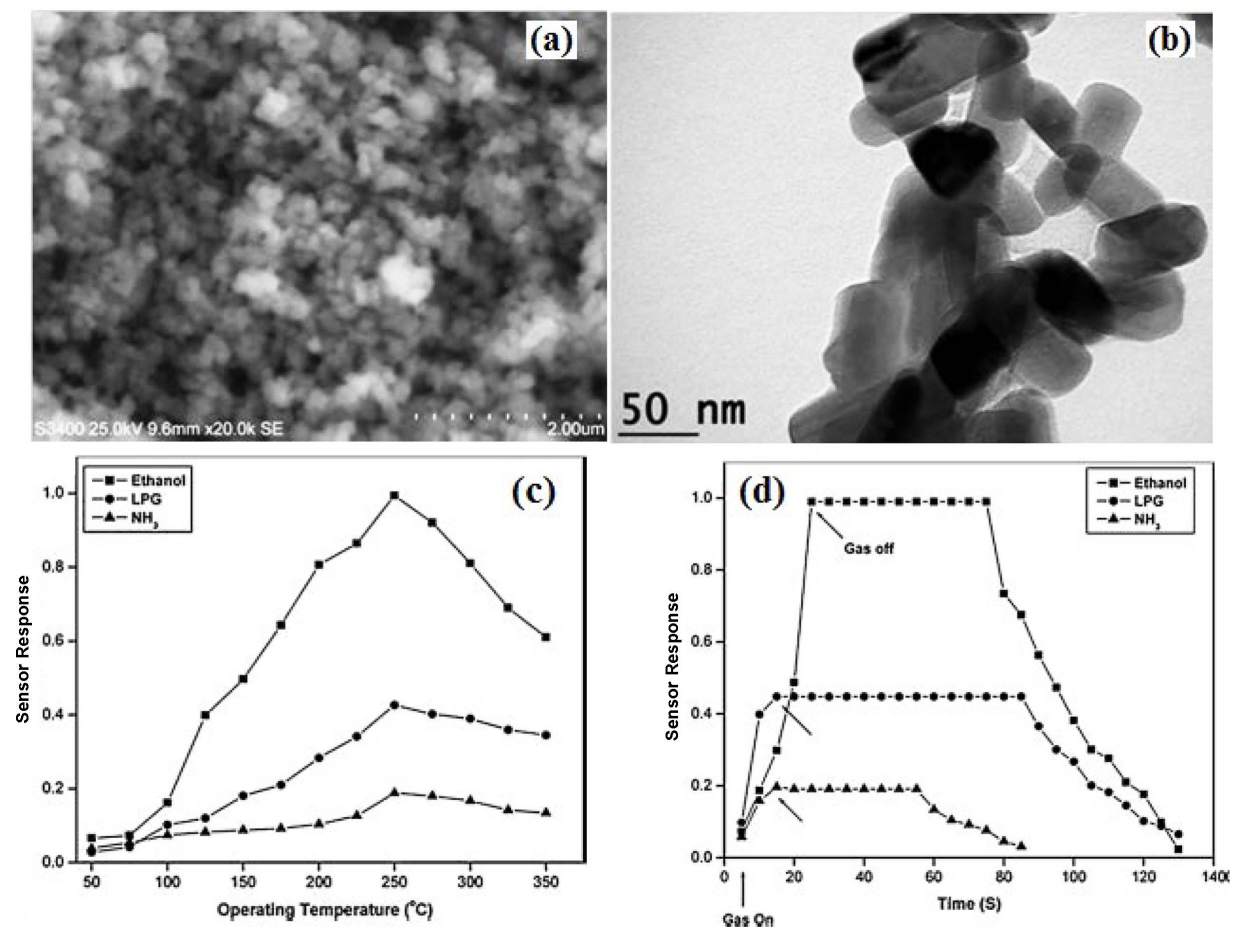

Fig. 12. (a), (b) SEM and TEM micrograph of $\mathrm{AlNbO}_{4}$ nanopowder obtained at $900^{\circ} \mathrm{C}$. (c) The esponse of $\mathrm{AlNbO}_{4}$ sensor with the different concentrations of $\mathrm{C}_{2} \mathrm{H}_{5} \mathrm{OH}, \mathrm{LPG}$ and $\mathrm{NH}_{3}$ at their optimum operating temperatures. (d) response of $\mathrm{AlNbO}_{4}$ sensor as a function of time at their optimum operating temperatures for $\mathrm{C}_{2} \mathrm{H}_{5} \mathrm{OH}, \mathrm{LPG}$ and $\mathrm{NH}_{3}$ gases. Reprinted with permission from reference. ${ }^{67)}$ 
ppm range, with a response time in second range as shown in Fig. 12(d).

\section{9. $\mathrm{FeNbO}_{4}$ material based gas sensor}

Semiconductor mixed metal oxide is one of the most interesting materials for gas sensing applications. In particular, mesoporous mixed oxide materials have been extensively investigated in the last two decades because of their uniform pore sizes, tuneable pore structures, ease of functionalization and large surface areas. Beyond the most-investigated silica and carbon based materials, metal oxides have attracted considerable interest due to their more diverse electronic functionality. Recently, $\mathrm{FeNbO}_{4}$ composite oxide was found to be more effective in terms of better sensitivity and selectivity to reducing gases. In addition, $\mathrm{FeNbO}_{4}$ semiconducting oxides have been studied extensively for a variety of applications. These include photo anode materials with potential applications in the conversion of solar energy and gas sensors. Moreover, they are well known as the key precursor for successful preparation of single phase perovskite $\mathrm{Pb}\left(\mathrm{Fe}_{1 / 2} \mathrm{Nb}_{1 / 2}\right) \mathrm{O}_{3}$, which is important for multilayer ceramic capacitor applications. $\mathrm{FeNbO}_{4}$, as a functional ntype semiconductor, has stimulated great research interest due to its unique optical and electrical properties. It exhibits semiconducting and magnetic behavior owing to coexistence of $\mathrm{Fe}^{2+}$ and $\mathrm{Fe}^{3+}$ ions. Most importantly, $\mathrm{FeNbO}_{4}$ structure has been established as a promising material for detecting gases. ${ }^{68,69)}$ Therefore, we reported for the first time ethanol gas sensing phenomena observed in mesoporous nanocrystalline $\mathrm{FeNbO}_{4}$, prepared by the niobium-citrate complex process. ${ }^{70)}$ Products obtained in this way are generally more homogenous, have higher surface area and finer particle size. Most importantly, it exhibits mesoporosity, higher degree of crystallinity and purity along with lower temperature sinterability than that of powders prepared by conventional methods. These properties enhance ethanol sensing of $\mathrm{FeNbO}_{4}$ prepared by niobium-citrate complex process. The SEM results (Fig. 13(a)) showed that the sample consists spherical particles with uniform grain size distribution. The sensitivity results (as shown in Fig. 13(b) - (d)) revealed that $\mathrm{FeNbO}_{4}$ had better response for $\mathrm{C}_{2} \mathrm{H}_{5} \mathrm{OH}$ at relatively lower operating temperature of $200^{\circ} \mathrm{C}$. The response time of $\mathrm{C}_{2} \mathrm{H}_{5} \mathrm{OH}$ was less than $20 \mathrm{~s}$. The high sensitivity and selectivity characteristic of $\mathrm{FeNbO}_{4}$ based sensor is related to the acid-base properties of the sensing surface. The presences of $\mathrm{Fe}$ atom enhance the basic sites in $\mathrm{FeNbO}_{4}$ surface and promote the sensitivity of the material to ethanol vapor in a very selective way. However, the rate of the surface reaction is in proportion to the number of available adsorption sites on the outer surface of the sensing mate-
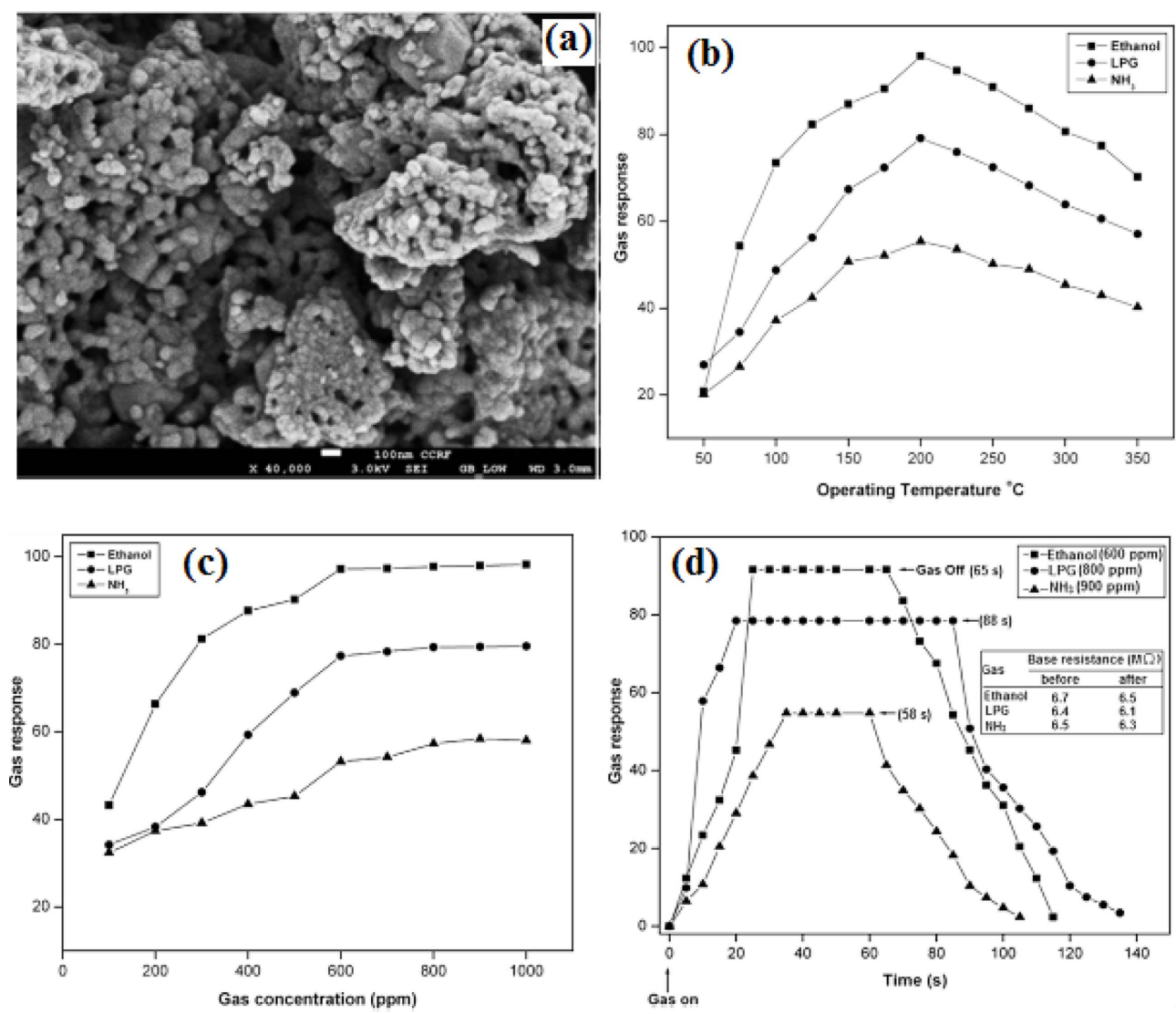

Fig. 13. (a) $\mathrm{SEM}$ micrograph of $\mathrm{FeNbO}_{4}$ nanopowder powder obtained at $800^{\circ} \mathrm{C}$ (b) gas sensing characteristics of $\mathrm{FeNbO}_{4}$ sensor for ethanol, $\mathrm{NH}_{3}$ and LPG as a function of various operating temperatures. (c) Sensor response with different concentrations of ethanol, $\mathrm{NH}_{3}$ and $\mathrm{LPG}$ at their optimum operating temperatures. (d) Ethanol, $\mathrm{NH}_{3}$ and LPG gas response of $\mathrm{FeNbO}_{4}$ sensor at their optimum operating temperatures. Reprinted with permission from reference. ${ }^{70)}$ 
rial. Hence, high surface area, high surface atomic activity, smaller grain size, lower activation energy and mesoporous structure of the $\mathrm{FeNbO}_{4}$ can greatly enhance the number of the adsorption sites. Additionally, niobium oxides possess a vast reservoir of mobile lattice oxygen, which is capable of increasing active selective sites during gas adsorption and enchaining the response towards ethanol.

\section{Metal Oxide Composites for Gas Sensor}

Recently, accelerated developments in nanotechnology and the extension of new nanostructured material syntheses have been improving the performance and utilization of semiconductor materials in sensing applications. Beyond the most investigated functional nanomaterial, p-type nickel oxide ( $\mathrm{NiO}$ ) was found to possess gas sensing activity. ${ }^{71)}$ However, to enhance gas sensitivity and selectivity, various additive based composites have been used. These additives could act as promoters, catalysts, surface sites for adsorption of oxygen and gases to be detected by promoting the improvement of porosity of the gas sensing matrix. Earlier works revealed that a few noble metals or transition metals (namely $\mathrm{Pt}, \mathrm{Ru}, \mathrm{Fe}, \mathrm{Mn}, \mathrm{Ni}, \mathrm{Al}, \mathrm{Cr}, \mathrm{Co}, \mathrm{Bi}$, etc) additive based composites significantly affected both electrophysical and gas sensing characteristics of metal oxides. In particular, $\mathrm{NiO}$ always contains defects; it is thermodynamically stable only if it contains defects. ${ }^{72)}$ The charge of the missing metal ions is compensated by holes on adjacent oxygen atoms. It has attracted considerable interest due to its wide range of practical applications, including dye-sensitized photocathodes, smart windows, super-capacitors, antimicrobial activity, catalysts and fuel cell electrodes. ${ }^{73)}$ However, the sensor performance of $\mathrm{NiO}$ depends on the number of free electrons in the outermost shells, which is greatly influenced by the change in resistance of the sensor. NiO, having in this form the $\mathrm{Ni}^{2+}$ ion, has a $3 \mathrm{~d}^{8}$ electronic configuration, and its triply degenerate state $\left(t_{2 g}\right)$ is filled, with one free electron in a doubly degenerate $\left(\mathrm{e}_{\mathrm{g}}\right)$ state; these free electrons facilitate the electron transport mechanism. Therefore, $\mathrm{NiO}$ has been widely used as the material for many gases sensing reactions. ${ }^{74-78)}$

\subsection{PdO-loaded NiO heteromixtures for gas sensing application}

To improve the $\mathrm{H}_{2} \mathrm{~S}$ sensing characteristics of the wide band gap $(3.83 \mathrm{eV})$ semiconductor $\mathrm{NiO}$, various modification methods have been commonly employed. Among the modification method, the formation of narrow $(\mathrm{PdO} 1.08 \mathrm{eV})$ and wider band gap (NiO $3.83 \mathrm{eV}$ ) heterojunctions could facilitate the electron-hole separation and enhance the interfacial charge transfer efficiency between donor and acceptor states, which help to improve the sensing characteristics. For this reason, we synthesized $\mathrm{NiO}$ and different wt.\% PdO-loaded $\mathrm{NiO}$ heteromixtures for gas sensing application by using a simple metal-citrate complex technique. ${ }^{79)}$ Gas sensing performances, the experimental results indicated that the 5 wt.\% PdO- doped $\mathrm{NiO}$ nanopowder based sensor exhibited a high response and repeatability towards 100 ppm $\mathrm{H}_{2} \mathrm{~S}(95 \%)$ at a relatively low temperature of $60^{\circ} \mathrm{C}$. It also was found that the $5 \mathrm{wt} . \% \mathrm{PdO}$-doped NiO heteromixture based sensor was more selective and had a faster response to $\mathrm{H}_{2} \mathrm{~S}$ than to other interfering gases.

\subsection{La-loaded $\mathrm{ZnO}$ composites for gas sensing appli- cation}

To meet the increasing demand for $\mathrm{CO}_{2}$-sensing materials, it is essential to develop new, inexpensive materials with a high $\mathrm{CO}_{2}$ response. Among the various $\mathrm{CO}_{2}$ sensing methods, semiconductor-based sensing systems are one of the most promising, compact, low-cost methods for $\mathrm{CO}_{2}$ detection. Semiconductor metal oxides, such as $\mathrm{SnO}_{2}, \mathrm{ZnO}$, and $\mathrm{CuO}$, are attractive candidates for the detection of different kinds of gases. ${ }^{80}$ Among the various semiconductor metal oxides, nanostructed (high surface/volume ratio), wide-band-gap (3.4 eV) $\mathrm{ZnO}$ has attracted significant attention because of its unique electronic, optical, and magnetic properties, which make it useful in a wide range of technological applications such as hydrogen storage, ${ }^{81)}$ piezoelectric devices, ${ }^{82)}$ batteries, ${ }^{83)}$ and gas sensors. ${ }^{84)}$ Moreover, in gas sensing, a metal oxide requires a catalyst to be depos-
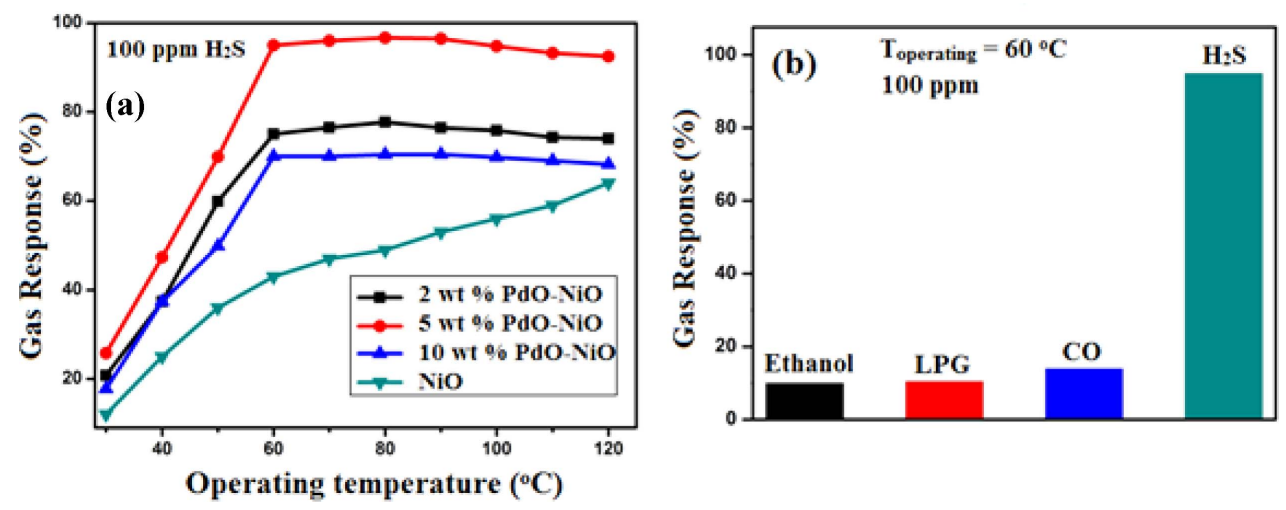

Fig. 14. (a) The relative resistance changes of the sensors exposed to $100 \mathrm{ppm}$ concentration of $\mathrm{H}_{2} \mathrm{~S}$ gas as a function of operating temperature (b) response of $5 \%$ PdO-doped $\mathrm{NiO}$ sensor with various interfering gases at $60^{\circ} \mathrm{C}$. Reprinted with permission from reference. ${ }^{79}$ 
ited on the sensor surface to accelerate the reaction and increase the sensitivity In particular, La can act as the catalyst and modify the electrical properties of base materials and sensor characteristics. The performance of $\mathrm{ZnO}$ in response to $\mathrm{CO}_{2}$ is greatly improved by the addition of $\mathrm{La}^{85}$ ) The better performance is due to the $\mathrm{p}$-n junction between n-type $(\mathrm{ZnO})$ and p-type $\left(\mathrm{La}_{2} \mathrm{O}_{3}\right)$ materials. Moreover, La (117 pm) has a greater ionic radius than $\mathrm{Zn}(88 \mathrm{pm})$; hence, it can be loaded into the pure structure of $\mathrm{ZnO}$ to create large lattice distortion. Furthermore, metal oxides contain acid/base surface sites, which control the adsorption and desorption properties of the gas molecules. ${ }^{86-88)}$ The basic surface sites of La can enhance the adsorption of acidic $\mathrm{CO}_{2}$, which may increase the response of La-loaded base materials. In this respect, D. H. Kim et al. reported the $\mathrm{LaCl}_{3}$ coated with commercially available tin oxide surface shows the highest sensitivity to $\mathrm{CO}_{2}$ gas by heat treating at $1000^{\circ} \mathrm{C}^{89)}$ Furthermore, A. Marsal et al. investigate $\mathrm{CO}_{2}$ sensing properties of $\mathrm{La}$ doped $\mathrm{SnO}_{2}$, and a significant response change can be obtained by La doped $\mathrm{SnO}_{2}$ rather than the undoped $\mathrm{SnO}_{2}$ sensor. ${ }^{90)}$ Among the various synthesis methods, the hydrothermal approach has been widely adopted because it is a simple, high-yield, and more controllable process that offers higher surface areas and low-temperature sinterability of the synthesized material compared to powders prepared by the previously mentioned methods. In previous research, pure $\mathrm{ZnO}$ and La-loaded $\mathrm{ZnO}$ gas sensor materials were synthesized by a simple hydrothermal method. ${ }^{15)}$ SEM image of the pure $\mathrm{ZnO}$ and 50 at\% Laloaded $\mathrm{ZnO}$ nanopowders revealed interesting morphologi-

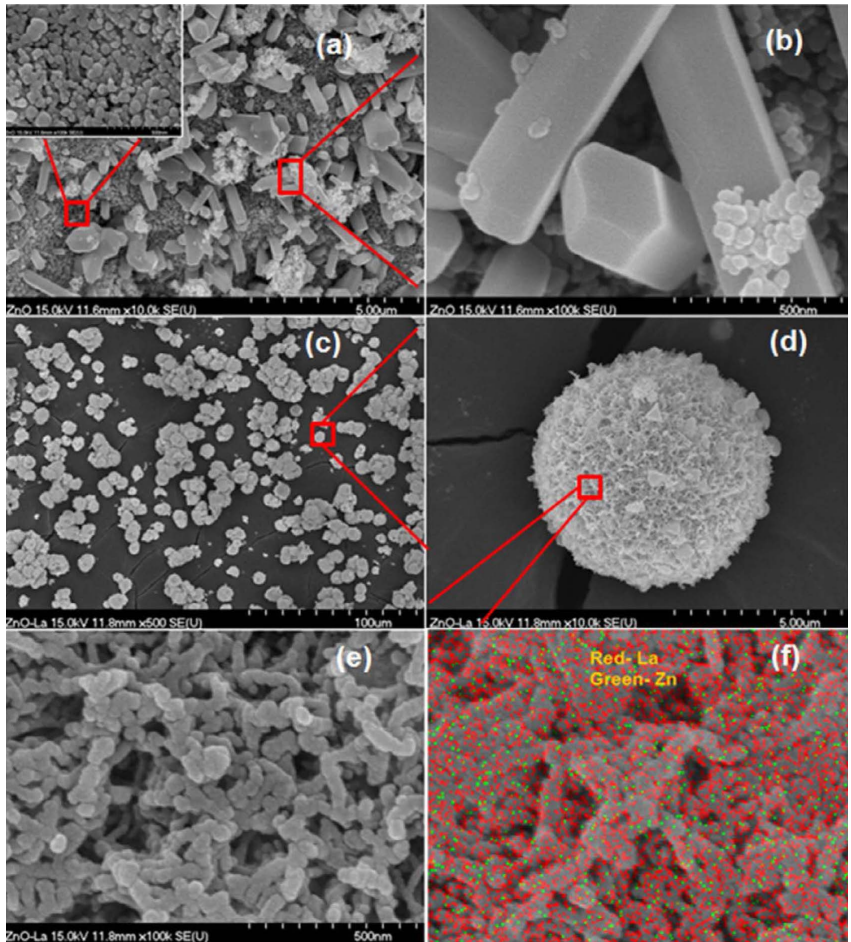

Fig. 15. (a) Shows low-magnification SEM images of the pure $\mathrm{ZnO}$ nanopowder calcined at $500^{\circ} \mathrm{C}$. The inset in left-side SEM of (a) shows enlarged spherical particles of $\mathrm{ZnO}$ nanopowder, (b) SEM image showing the magnified view of the dense $\mathrm{ZnO}$ nanorods (c-e) shows the low and high-magnification SEM image of 50\% La-loaded $\mathrm{ZnO}$ nanopowder calcined at $500^{\circ} \mathrm{C}$, and (f) corresponding EDX mapping spectra. Reprinted with permission from reference. ${ }^{15)}$
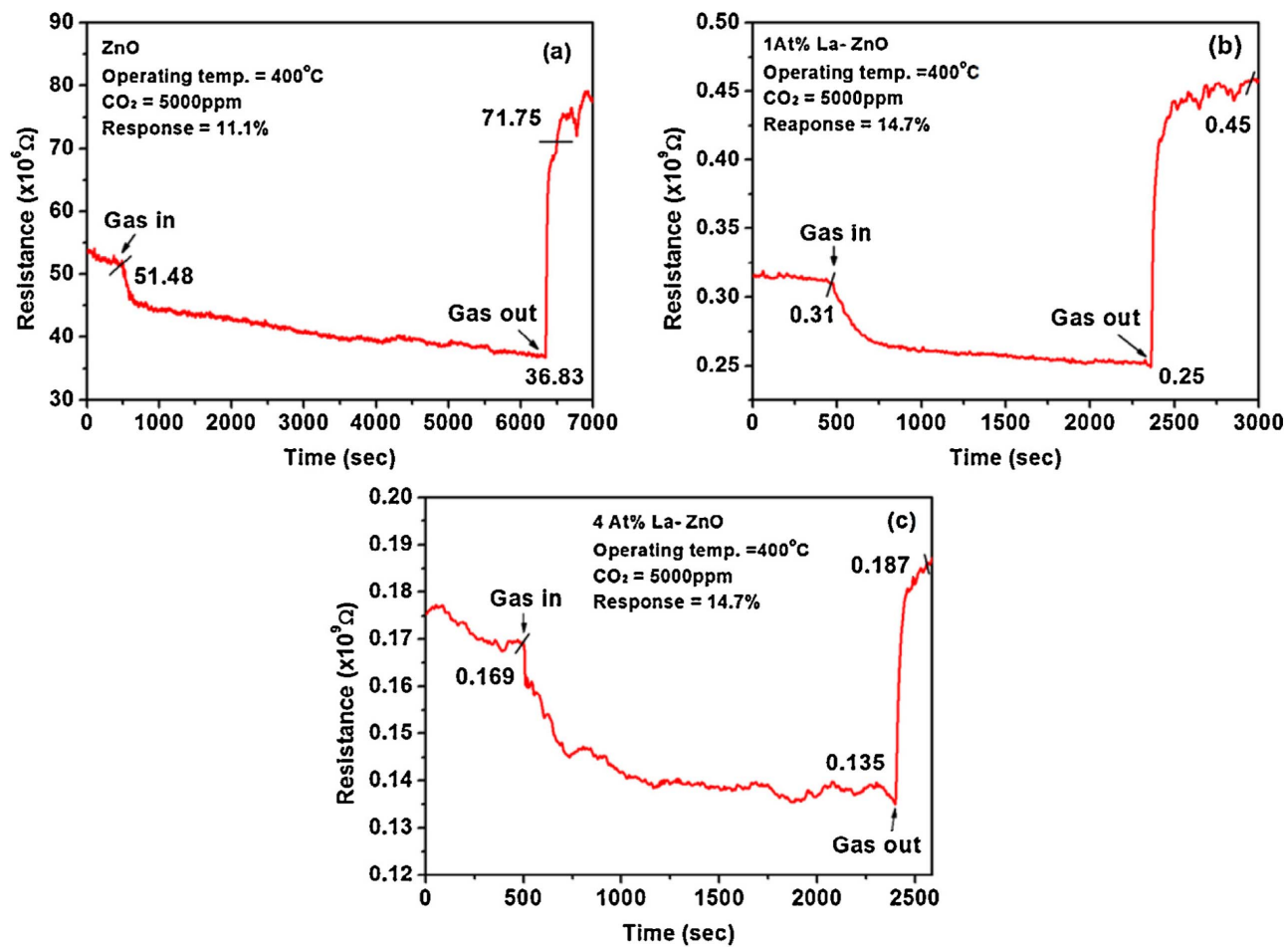

Fig. 16. (a) The response of pure $\mathrm{ZnO}$ nanopowder based sensor with $5000 \mathrm{ppm} \mathrm{CO}_{2}$ concentration at $400^{\circ} \mathrm{C}$, (b) 1 at $\%$ La-loaded $\mathrm{ZnO}$ based sensor and (c) 4 at\% La-loaded $\mathrm{ZnO}$ based sensor. Reprinted with permission from reference. ${ }^{15)}$ 
cal characteristics as shown in Fig. 14(a-f). The prepared materials were utilized as $\mathrm{CO}_{2}$ gas sensing analysis, and the results indicated that the pure $\mathrm{ZnO}$ nanopowder to 5000 ppm of $\mathrm{CO}_{2}$ was $11 \%$ at $400^{\circ} \mathrm{C}$, as shown in Fig. 15 (a). Fig. 15(b) and (c) clearly show that the $\mathrm{CO}_{2}$ response of 1 and 4 at\% La-loaded $\mathrm{ZnO}$ were 14.7 and $20 \%$, which are higher than the response of pure $\mathrm{ZnO}$ at the same operating temperature of $400^{\circ} \mathrm{C}$. The results indicate that the dopant (La) effectively influenced the sensing properties of the $\mathrm{ZnO}$ material. The $\mathrm{CO}_{2}$ response of the $\mathrm{ZnO}$ was markedly increased (37\%) for 10 at\% La loaded $\mathrm{ZnO}$ based sensor at operating temperature of $400^{\circ} \mathrm{C}$ as shown in the Fig. 16 (a). Furthermore, a systematic investigation of variation in sensor response as a function of gas concentration was carried out, as shown in in Fig. 16(b). To further enhance the $\mathrm{CO}_{2}$ response, we attempted to increase the La concentration, leading to a gradual enhancement of the $\mathrm{CO}_{2}$ response that reached a maximum response (65\%) after loading around 50 at\% $\mathrm{La}$ in $\mathrm{ZnO}$ at an operating temperature of $400^{\circ} \mathrm{C}$, as shown in Fig. 16(c-d). The enhanced performance is attributed to the large lattice distortion and the concerted effect between the $\mathrm{Zn}$ and La-active materials is a key factor in improving the $\mathrm{CO}_{2}$ adsorption and reactivity on the surface. The proposed material is very promising for $\mathrm{CO}_{2}$ monitoring environment due to their high sensitivities and short response time.

\subsection{Sensing mechanism for mixed metal oxides}

Bimetallic systems are of great interest in the design of new materials with industrial applications in the areas of catalysis, electrochemistry and microelectronics. Suitably designed bimetallic catalysts utilize the beneficial effect of the interaction between the two metals for the enhancement of both catalytic activities. ${ }^{91)}$ It is well-known that response properties and selectivity depend on the nature of active sites the in structure of the sensor surface. Both base and acid sites can contribute to the adjustment of sensor properties. Moreover, the surface acidity of metal oxides can play an important role the in selective sensing of gases. Mixed metal oxide surfaces are expected to exhibit modified chemical properties compared to pure metal surfaces. The response behavior of the selective sensing of gas could be correlated closely to the surface redox ability of mixed metal oxide catalysts.

The semiconductor gas sensing mechanism of mixed metal oxide is based on the reactions between the surface of the material and the interaction of gas molecules, which causes a change in the material resistance due to a charge transfer between the adsorbates and the adsorbent. Normally, the mobile lattice oxygen acts as the selective site in gas adsorption. The partially reduced metal ion $\left(\mathrm{M}^{+}\right)$to possess vast reservoir of oxygen generates highly mobile charge carriers. Jerzy Haber ${ }^{92)}$ reported that at temperatures lower than $140^{\circ} \mathrm{C}$, the catalysis surface is covered by reactive electrophilic $\mathrm{O}^{-}$and $\mathrm{O}_{2}^{-}$, whereas at temperatures higher than $140^{\circ} \mathrm{C}$, only nucleophilic $\mathrm{O}^{2-}$ species are present at the surface. The adsorption of $\mathrm{O}^{-}$was the most interesting process in sensors, because these oxygen ions were more reactive and thus made the material more sensitive to the presence of reducing gases. When the sensor material was exposed to gases, the superficial reactions of with the oxygen species caused more electrons to return to the conduction band (depending on nature of gas; donor/acceptor of electrons); the electrons injected into the surface recombined with some of the holes, thus reducing the concentration of the charge carriers and increasing the resistance of the p-type sensor materials. Therefore, the improved ionosorption of oxygen species due to the spill over effect will promote the enhanced response of the sensor to the reducing gases. ${ }^{13}$

Sensor materials are classified as n-type or p-type, depending on whether they show an increase or decrease in electrical conduction, when they are exposed to oxidizing or reducing test gas. Here, we briefly introduce to the sensing mechanism of p-type mixed metal oxides in $\mathrm{NH}_{3}$ is given based on the example of $\mathrm{NiV}_{2} \mathrm{O}_{6}$. The surface reactions between the oxygen and the sensor material can be described as follows: ${ }^{13)}$

$$
\begin{aligned}
& \mathrm{O}_{2}(\text { gas }) \leftrightarrow \mathrm{O}_{2}(\text { ads }) \\
& \mathrm{O}_{2}(\text { ads })+\mathrm{e}^{-} \leftrightarrow \mathrm{O}_{2}^{-} \\
& \mathrm{O}_{2}{ }^{-}+\mathrm{e}^{-} \leftrightarrow 2 \mathrm{O}^{-}
\end{aligned}
$$

The typical sensing mechanism of p-type semiconducting sensor is shown in Fig. 17. When the sensor surface are exposed to air, oxygen molecules will adsorb on the surface of sensor and form $\mathrm{O}^{-}$ions by capturing electrons from the conduction band. This leads to the formation of a charge accumulation layer at the shell by the following reaction and as seen in the energy level diagram shown in Fig. 17(a).

(a)

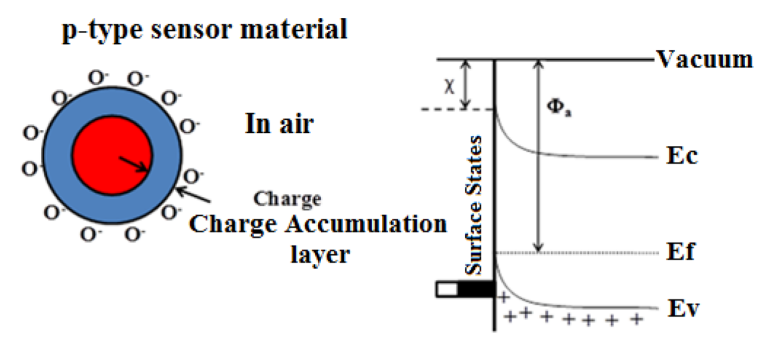

(b)

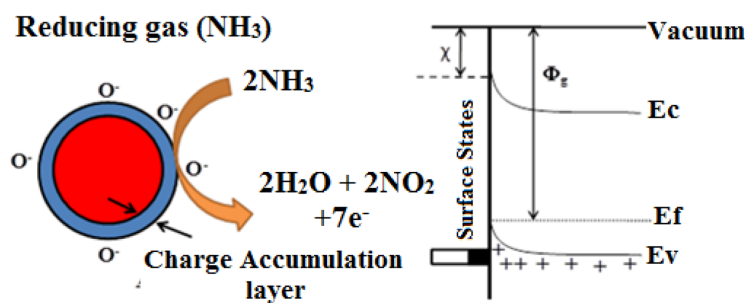

Fig. 17. Schematic showing (a) interaction between oxygen and sensor grain and corresponding energy band diagram; (b) interaction between $\mathrm{NH}_{3}$ and sensor grain and corresponding energy band diagram. 


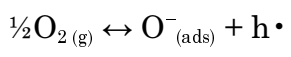

The equivalent band diagram is represented as an upward band bending, see Fig. 17(a). When the sensor grains are exposed to the reducing gas $\left(\mathrm{NH}_{3}\right)$ gas, the adsorbed $\mathrm{O}^{-}$species interacts with the $\mathrm{NH}_{3}$, resulting in the release of captured electrons according to the following reaction.

$$
2 \mathrm{NH}_{3}+7 \mathrm{O}^{-}(\mathrm{ads}) \leftrightarrow 3 \mathrm{H}_{2} \mathrm{O}+2 \mathrm{NO}_{2}+7 \mathrm{e}^{-}
$$

The charge carrier accumulation layer near the surface is thinned by the electrochemical interaction between $\mathrm{O}^{-}(\mathrm{ads})$ and reducing gases, which in turn increases the sensor resistance. Upon exposure to a reducing gas, the density of p-type charge carriers (positive holes) would decrease due to the surface adsorption and chemical reaction between the gas and the oxygen adsorbates (electron acceptor), which is represented in terms of the lowering of upward band bending (Fig. 17(b)), which is the opposite to that seen with the n-type semiconductor gas sensors. Furthermore, $\mathrm{NiV}_{2} \mathrm{O}_{6}$ can have bivalent catalytic centers by assuming that charge transport might occur via the $\mathrm{Ni}^{+}-\mathrm{O}-\mathrm{Ni}^{2+}$ framework with all $\mathrm{V}$ ions in $\mathrm{a}+5$ state or $\mathrm{V}^{4+}-\mathrm{O}-\mathrm{V}^{5+}$ framework with all $\mathrm{Ni}$ ions in a +2 state. Moreover, higher sensing activity of $\mathrm{NiV}_{2} \mathrm{O}_{6}$ nanopowder may be attributed to the fact that besides the one component sites $\mathrm{Ni}^{1+}-\mathrm{O}-\mathrm{Ni}^{2+}$ and $\mathrm{V}^{5+}-\mathrm{O}-\mathrm{V}^{4+}$, there will be also the mixed sites $\mathrm{Ni}^{1+}-\mathrm{O}-\mathrm{V}^{5+}$ and/or $\mathrm{Ni}^{2+}-\mathrm{O}-\mathrm{V}^{4+}$ ion pairs as a result of mutual charge interaction. The presence of fraction of reduced $\mathrm{V}^{4+}$ ions in the system is capable to reduce $\mathrm{Ni}^{2+}$ major centres partly to ions of lower oxidation, whereas $\mathrm{Ni}^{1+}$ minor centres being more active species in $\mathrm{NH}_{3}$ sensing reaction. Here the presence of vanadium atom seems to stabilize the catalyst structure against oxidation as well as reduction and to permit a very strongly oxidized/reduced sensing material. This leads to easy recovery of the original state of the sensing material. This means that the observed changes of the electrical resistance are probably due to the changes of valence state of catalytically active components of the sensor material. The role of the Nickel in enhancing the sensitivity and response rate of the sensor element could be due to the increase the acid sites, which catalyses the oxidation of $\mathrm{NH}_{3}{ }^{13)}$

\section{Conclusions}

In summary, the gas sensing process is strongly related to the surface reactions. Different metal oxide based materials have different reaction activation to the target gases. Mixed metal oxides usually show better gas response than the single component if the catalytic actions of the mixed metal complement each other. Transitions metal or noble metal additives with high-effective oxidation catalytic activity can be used to enhance the sensitivity of pure metal oxides due to the "spillover effect". Moreover, a good catalyst supporting materials are also a pivotal point to determine a selective response of various gases. So, the structure of metal oxide layers is very important. The sensing mechanism is based on the surface reaction of the particles with the exposed gas by adsorption and desorption mechanism. The adsorption being a surface effect, surface area plays an important role in the sensing mechanism. The High surface areas are necessary to obtain highly-dispersed catalyst particles. In the nanosized materials, a large fraction of the atoms are present at the surface, Therefore, nanostructure with porosity seems to be the standard structure of sensor materials and are enhance the gas-sensing properties of mixed metal oxides semiconductor.

\section{Acknowledgments}

This research was supported by the Ministry of Trade, Industry \& Energy (MOTIE), Korea Institute for Advancement of Technology (KIAT) through the Encouragement Program for The Industry of Economic Cooperation Region (No. R0004802).

\section{REFERENCES}

1. M. F. Struve, J. N. Brisbois, R. ArdenJames, M. W. Marshall, and D. C. Dorman, "Neurotoxicological Effects Associated with Short-Term Exposure of Sprague-Dawley Rats to Hydrogen Sulfide," Neurotoxicology, 22 [3] 375-85 (2001).

2. Y. G. Yu, D. K. Ning, and L. G. Qian, "The First-Principle Calculation of $\mathrm{H}_{2} \mathrm{~S}$ Adsorption and Decomposition on the ZnO (0001) Surface," Chin. J. Struct. Chem., 29 1139-46 (2010).

3. C. Balamurugan and D. W. Lee, "Perovskite Hexagonal $\mathrm{YMnO}_{3}$ Nanopowder as p-type Semiconductor Gas Sensor for $\mathrm{H}_{2} \mathrm{~S}$ Detection," Sens. Actuators, B, 221 857-66 (2015).

4. Y. Zhang, Z. H. Tang, Z. Ren, S. L. Qu, M. H. Liu, L. S. Liu, and Z. S. Jiang, "Hydrogen Sulfide, the Next Potent Preventive and Therapeutic Agent in Aging and AgeAssociated Diseases," Mol. Cell. Biol., 33 [6] 1104-13 (2013).

5. C. Balamurugan, S. Arunkumar, and D.-W. Lee, "Hierarchical 3D Nanostructure of $\mathrm{GdInO}_{3}$ and Reduced-GrapheneDecorated $\mathrm{GdInO}_{3}$ Nanocomposite for CO Sensing Applications," Sens. Actuators, B, 234 155-66 (2016).

6. C. Balamurugan, A. R. Maheswari, and D.-W. Lee, "Structural, Optical, and Selective Ethanol Sensing Properties of p-type Semiconducting $\mathrm{CoNb}_{2} \mathrm{O}_{6}$ Nanopowder," Sens. Actuators, B, 205 [15] 289-97 (2014).

7. C. Balamurugan, D. W. Lee, A. R. Maheswari, and M. Parmar, "Porous Wide Band Gap $\mathrm{BiNbO}_{4}$ Ceramic Nanopowder Synthesised by Low Temperature Solution-Based Method for Gas Sensing Applications," RSC Adv., 4 54625-30 (2014).

8. F. Menil, V. Coillard, and C. Lucat, "Critical Review of Nitrogen Monoxide Sensors for Exhaust Gases of Lean Burn Engines," Sens. Actuators, B, 67 [1-2] 1-23 (2000).

9. S. Zhuiykov and N. Miura, "Development of ZirconiaBased Potentiometric $\mathrm{NO}_{\mathrm{x}}$ Sensors for Automotive and Energy Industries in the Early 21st. Century: What are the Prospects for Sensors?," Sens. Actuators, B, 121 [2] 639-51 (2007). 
10. A. R. Phani, S. Manorams, and V. J. Rao, "Preparation, Characterization and Electrical Properties of $\mathrm{SnO}_{2}$ Based Liquid Petroleum Gas Sensor," Mater Chem. Phys., 58 [2] 101-8 (1999).

11. Y. D. Wang, X. H. Wu, and Z. L. Zhou, "Novel High Sensitivity and Selectivity Semiconductor Gas Sensor Based on the $\mathrm{p}+\mathrm{n}$ Combined Structure," Solid-State Electron., 44 [9] 1603-7 (2000).

12. S. K. Pandey, K. H. Kim, and K. T. Tang, "A Review of Sensor-Based Methods for Monitoring Hydrogen Sulfide," Trends Anal. Chem., 32 87-99 (2012).

13. C. Balamurugan and D. W. Lee, "A Selective $\mathrm{NH}_{3}$ Gas Sensor Based on Mesoporous p-type $\mathrm{NiV}_{2} \mathrm{O}_{6}$ Semiconducting Nanorods Synthesized Using Solution Method," Sens. Actuators, B, 192 414-22 (2014).

14. T. H. Kim, J. W. Yoon, and J. H. Lee, "Avolatile Organic Compound Sensor Using Porous $\mathrm{Co}_{3} \mathrm{O}_{4}$ Spheres," J. Korean Ceram. Soc., 53 [2] 134-38 (2016).

15. Y.-J. Jeong, C. Balamurugan, and D.-W. Lee, "Enhanced $\mathrm{CO}_{2}$ Gas-Sensing Performance of $\mathrm{ZnO}$ Nanopowder by La Loaded during Simple Hydrothermal Method," Sens. Actuators, B, 229 288-96 (2016).

16. Z. U. Abideen, J.-H. Kim, J. H. Lee, J. Y. Kim, A. Mirzaei, H. W. Kim, and S. S. Kim, "Electrspun Metal Oxide Composite Nanofibers Gas Sensors: A Review," J. Korean Ceram. Soc., 54 [5] 366-79 (2017).

17. Z. Hao, Qi, M. Chuai, B. Xiao, T. Yang, Y. Luo, and M. Zhang, "Synthesis of Dandelion-Like NiO Hierarchical Structures Assembled with Dendritic Units and their Performances for Ethanol Gas Sensing," New J. Chem., 39 7873-78 (2015).

18. N. Savage, B. Chwieroth, A. Ginwalla, B. R. Patton, S. A. Akbar, and P. K. Dutta, "Composite n-p Semiconducting Titanium Oxides as Gas Sensors," Sens. Actuators, B, 79 [1] 17-27 (2001).

19. G. Korotcenkov, "Practical Aspects in Design of OneElectrode Semiconductor Gas Sensors: Status Report," Sens. Actuators, B, 121 [2] 664-78 (2007).

20. A. R. Phani, S. V. Manorama, and V. J. Rao, "X-Ray Photoelectron Spectroscopy Studies on Pd Doped $\mathrm{SnO}_{2}$ Liquid Petroleum Gas Sensor," Appl. Phys. Lett., 71 [16] 2358-60 (1997).

21. C. Moure and O. Pena, "Recent Advances in Perovskites: Processing and Properties," Prog. Solid State Chem., 43 [4] 123-48 (2015).

22. J. Malowney, N. Mestres, X. Borrise, A. Calleja, R. Guzman, J. Llobet, J. Arbiol, T. Puig, X. Obradors, and J. Bausells, "Functional Oxide Nanostructures Written by EBL on Insulating Single Crystal Substrates," Microelectron. Eng., 110 94-9 (2013).

23. M. A. Peña and J. L. G. Fierro, "Chemical Structures and Performance of Perovskite Oxides," Chem. Rev., 101 [7] 1981-2018 (2001).

24. S. Mathur, H. Shen, N. Lecerf, A. Kjekshus, H. Fjellvag, and G. F. Goya, "Nanocrystalline Orthoferrite $\mathrm{GdFeO}_{3}$ from a Novel Heterobimetallic Precursor," Adv. Mater., 14 [19] 1405-9 (2002).

25. S. Palimar, S. D. Kaushik, V. Siruguri, D. Swain, A. E. Viegas, C. Narayana, and N. G. Sundaram, "Investigation of Ca Substitution on the Gas Sensing Potential of $\mathrm{LaFeO}_{3}$ Nanoparticles towards Low Concentration $\mathrm{SO}_{2}$ Gas," Dalton Trans., 45 13547-55 (2016).

26. X. Li, C. Tang, M. Ai, L. Dong, and Z. Xu, "Controllable Synthesis of Pure-Phase Rare-Earth Orthoferrites Hollow Spheres with a Porous Shell and their Catalytic Performance for the CO + NO Reaction," Chem. Mater., 22 487989 (2010).

27. V. V. Kharton, A. A. Yaremchenko, A. V. Kovalevsky, A. P. Viskup, E. N. Naumovich, and P. F. Kerko, "PerovskiteType Oxides for High-Temperature Oxygen Separation Membranes," J. Membr. Sci., 163 [2] 307-17 (1999).

28. E. Traversa, S. Matsushima, G. Okada, Y. Sadaoka, Y. Sakai, and W. Watanabe, " $\mathrm{NO}_{2}$ Sensitive $\mathrm{LaFeO}_{3}$ Thin Films Prepared by r.f. Sputtering," Sens. Actuators, B, 25 [1-3] 661-64 (1995).

29. V. Bedekar, O. D. Jayakumar, J. Manjanna, and A. K. Tyagi, "Synthesis and Magnetic Studies of Nano-Crystalline $\mathrm{GdFeO}_{3}$, "Mater. Lett., 62 [23] 793-95 (2008).

30. R. Shukla, V. Grover, S. K. Deshpande, D. Jain, and A. K. Tyagi, "Synthesis and Structural and Electrical Investigations of a Hexagonal $\mathrm{Y}_{1-\mathrm{x}} \mathrm{Gd}_{\mathrm{x}} \mathrm{InO}_{3}(0.0 \leq \mathrm{x} \leq 1.0)$ System Obtained via Metastable C-Type Intermediates," Inorg. Chem., 52 [22] 13179-87 (2013).

31. D. H. Kuo and K. C. Huang, "Phase Composition and Properties of Solid Solutions of $\mathrm{GdFeO}_{3}$ - $\mathrm{GdInO}_{3}$ Bulks," Ceram. Int., 34 [6] 1503-7 (2008).

32. L. G. Ortiz, J. R. Gómez, J. M. F. Álvarez, H. G. Bonilla, M. L. Olvera, V. M. R. Betancourtt, Y. V. Gómez, A. G. Cervantes, and J. S. Salazar, "Synthesis, Characterization and Sensitivity Tests of Perovskite-Type $\mathrm{LaFeO}_{3}$ Nanoparticles in $\mathrm{CO}$ and Propane Atmospheres," Ceram. Int., 42 [16] 18821-27 (2016).

33. T. Tabari and H. Tavakkoli, "Fabrication and Characterization of Perovskite-Type Oxide $\mathrm{LaFe}_{0.9} \mathrm{Co}_{0.1} \mathrm{O}_{3}$ Nanoparticles and Its Performance in Aerobic Oxidation of Thiols to Disulfide," Chin. J. Catal., 33 [11] 1791-96 (2012).

34. J. Zhu and A. Thomas, "Perovskite-Type Mixed Oxides as Catalytic Material for NO Removal," Appl. Catal., B, 92 [3-4] 225-33 (2009).

35. B. B. V. Aken, T. T. M. Palstra, A. Filippetti, and N. A. Spaldin, "The Origin of Ferroelectricity in Magnetoelectric $\mathrm{YMnO}_{3}$, , Nat. Mater., 3 164-70 (2004).

36. J. Park, J.-G. Park, G. S. Jeon, H. Y. Choi, C. Lee, W. Jo, R. Bewley, K. A. McEwen, and T. G. Perring, "Magnetic Ordering and Spin-Liquid State of $\mathrm{YMnO}_{3}$," Phys. Rev. B, 68 104426-6 (2003).

37. Y. Aikawa, T. Katsufuji, T. Arima, and K. Kato, "Effect of Mn Trimerization on the Magnetic and Dielectric Properties of Hexagonal $\mathrm{YMnO}_{3}$," Phys. Rev. B, 71 184418-22 (2005).

38. M. Zaghrioui, V. Ta Phuoc, R. A. Souza, and M. Gervais, "Polarized Reflectivity and Lattice Dynamics Calculation of Multiferroic $\mathrm{YMnO}_{3}$," Phys. Rev. B, 78 184305-12 (2008).

39. D. P. Kozlenko, S. E. Kichanov, S. Lee, J. G. Park, V. P. Glazkov, and B. N. Savenko, "High-Pressure Effect on the Crystal and Magnetic Structures of the Frustrated Antiferromagnet $\mathrm{YMnO}_{3}$," JETP Lett., 82 [4] 193-97 (2005).

40. N. Natarajan, V. Samuel, R. Pasricha, and V. Ravi, "A Coprecipitation Technique to Prepare $\mathrm{BaNb}_{2} \mathrm{O}_{6}$," Mater. 
Sci. Eng. B, 117 [2] 169-71 (2005).

41. R. Pasricha and V. Ravi, "Preparation of Nanocrystalline $\mathrm{MgNb}_{2} \mathrm{O}_{6}$ by Citrate Gel Method," Mater. Lett., 59 2146-48 (2005).

42. V. Ravi, "A Coprecipitation Technique to Prepare $\mathrm{SrNb}_{2} \mathrm{O}_{6}$," Mater. Charact., 55 [1] 92-5 (2005).

43. V. V. Deshpande, M. M. Patil, S. C. Navale, and V. Ravi, "A Coprecipitation Technique to Prepare $\mathrm{ZnNb}_{2} \mathrm{O}_{6}$ Powders," Bull. Mater. Sci., 28 [3] 205-7 (2005).

44. Y. Zhang, C. Liu, G. Pang, S. Jiao, S. Zhu, D. Wang, D. Liang, and S. Feng, "Hydrothermal Synthesis of a $\mathrm{CaNb}_{2} \mathrm{O}_{6}$ Hierarchical Micro/Nanostructure and Its Enhanced Photocatalytic Activity," Eur. J. Inorg. Chem., 2010 [8] 1275$82(2010)$

45. F. E. Osterloh, "Inorganic Materials as Catalysts for Photochemical Splitting of Water," Chem. Mater., 20 [1] 35-54 (2007).

46. S. N. Akihiko Kudo and H. Kato, "Overall Water Splitting into $\mathrm{H}_{2}$ and $\mathrm{O}_{2}$ under UV Irradiation on NiO-loaded $\mathrm{ZnNb}_{2} \mathrm{O}_{6}$ Photocatalysts Consisting of $\mathrm{d}^{10}$ and $\mathrm{d}^{0}$ Ions," Chem. Lett., 28 1197-98 (1999).

47. R. C. Pullar, "The Synthesis, Properties, and Applications of Columbite Niobates $\left(\mathrm{M}^{2+} \mathrm{Nb}_{2} \mathrm{O}_{6}\right)$ : A Critical Review," $J$. Am. Ceram. Soc., 92 [3] 563-77 (2009).

48. V. E. Henrich and P. A. Cox, The Surface Science of Metal Oxides; pp. 159-61, Cambridge University Press, New York, 1994.

49. J. R. Istas, R. de Borger, L. de Temmerman, Guns, K. Meeus-Verdinne, A. Ronse, P. Scokart, and M. Termonia, "Effect of Ammonia on the Acidification of the Environment", European Communities Rept. No. EUR 11857 EN (1988).

50. S. V. Krupa, "Effects of Atmospheric Ammonia $\left(\mathrm{NH}_{3}\right)$ on Terrestrial Vegetation: A Review," Environ. Pollut., 124 [2] 179-21 (2003).

51. Y. C. Liou, W. C. Tsai, and H. M. Chen, "Low-Temperature Synthesis of $\mathrm{BiNbO}_{4}$ Ceramics Using Reaction-Sintering Process," Ceram. Int., 35 [6] 2119-22 (2009).

52. D. Liu, Y. Liu, S. Q. Huang, and X. Yao, "Phase Structure and Dielectric Properties of $\mathrm{Bi}_{2} \mathrm{O}_{3}-\mathrm{ZnO}-\mathrm{Nb}_{2} \mathrm{O}_{5}$-based Dielectric Ceramics," J. Am. Chem. Soc., 76 [8] 2129-32 (1993).

53. H. C. Ling, M. F. Yan, and W. W. Rhodes, "High Dielectric Constant and Small Temperature Coefficient BismuthBased Dielectric Compositions," J. Mater. Res., 5 [8] 175262 (1990).

54. E. S. Kim and W. Choi, "Effect of Phase Transition on the Microwave Dielectric Properties of $\mathrm{BiNbO}_{4}$, J. Eur. Ceram Soc., 26 [10-11] 1761-66 (2006).

55. B. Timmer and O. W. Berg, "Ammonia Sensors and their Applications-A Review," Sens. Actuators, B, 107 [2] 66677 (2005).

56. T. Mokkelbost, H. L. Lein, P. E. Vullum, R. Holmestad, T. Grande, and M.-A. Einarsrud, "Thermal and Mechanical Properties of $\mathrm{LaNbO}_{4}$-Based Ceramics," Ceram. Int., 35 [7] 2877-83 (2009).

57. Y. J. Hsiao, T. H. Fang, Y. S. Chang, Y. H. Chang, C. H. Liu, L. W. Ji, and W. Y. Jywe, "Structure and Luminescent Properties of $\mathrm{LaNbO}_{4}$ Synthesized by Sol-Gel Process," J. Lumin., 126 [2] 866-70 (2007).
58. R. Haugsrud and T. Norby, "Proton Conduction in Rare Earth Ortho-Niobates and Orthotantalates," Nat. Mater., 5 193-96 (2006).

59. R. Hauigsrud and T. Norby, "High-Temperature Proton Conductivity in Acceptor-Doped $\mathrm{LaNbO}_{4}$," Solid State Ionics, 177 [13-14] 1129-35 (2006).

60. C. Balamurugan, D.-W. Lee, and A. Subramani, "Preparation and LPG-Gas Sensing Characteristics of p-type Semiconducting $\mathrm{LaNbO}_{4}$ Ceramic Material," Appl. Surf. Sci., 283 58-64 (2013).

61. Z. Zou, J. Ye, and H. Arakawa, "Photophysical and Photocatalytic Properties of $\operatorname{InMO}_{4}\left(\mathrm{M}=\mathrm{Nb}^{5+}, \mathrm{Ta}^{5+}\right)$ under Visible Light Irradiation," Mater. Res. Bull. 36 [7-8] 1185-93 (2001).

62. A. L. Petre, J. A. Perdigon-Melon, A. Gervasini, and A. Auroux, "Characterization and Reactivity of Group III Oxides Supported on Niobium Oxide," Catal. Today, 78 [1-4] 377-86 (2003).

63. Z. Zou, J. Ye, and H. Arakawa, "Structural Properties of $\mathrm{InNbO}_{4}$ and $\mathrm{InTaO}_{4}$ : Correlation with Photocatalytic and Photophysical Properties," Chem. Phys. Lett., 332 [3-4] 271-77 (2000).

64. Z. Zou, J. Ye, K. Sayama, and H. Arakawa, "Direct Splitting of Water under Visible Light Irradiation with an Oxide Semiconductor Photocatalyst," Nature, 414 625-27 (2001).

65. C. Balamurugan, E. Vijayakumar, and A. Subramania, "Synthesis and Characterization of $\mathrm{InNbO}_{4}$ Nanopowder for Gas Sensors," Talanta, 88 115-20 (2012).

66. C. Balamurugan, G. Bhuvanalogini, and A. Subramania, "Development of Nanocrystalline $\mathrm{CrNbO}_{4}$ Based p-type Semiconducting Gas Sensor for LPG, Ethanol and Ammonia," Sens. Actuators, B, 168 165-71 (2012).

67. C. Balamurugana, A. Subashinia, G. N. Chaudharib, and A. Subramania, "Development of Wide Band Gap Sensor Based on $\mathrm{AlNbO}_{4}$ Nanopowder for Ethanol," J. Alloys Compd., 526 110-15 (2012).

68. D. H. Dawson and D. E. Williams, "Gas-Sensitive Resistors: Surface Interaction of Chlorine with Semiconducting Oxides," J. Mater. Chem., 6 409-14 (1996).

69. V. Dusastre and D. E. Williams, "Gas-Sensitive Resistor Properties of the Solid Solution Series $\mathrm{Ti}_{x}\left(\mathrm{Sn}_{1-y} \mathrm{Sb}_{y}\right)_{1-x} \mathrm{O}_{2}(0$ $<x<1, y=0,0.01,0.05)$," J. Mater. Chem., 6 445-50 (1999).

70. C. Balamurugan, D. W. Lee, and A. Subramania, "Selective Ethanol Gas Sensing Behavior of Mesoporous n-type Semiconducting $\mathrm{FeNbO}_{4}$ Nanopowder Obtained by Niobium-Citrate Process," Curr. Appl. Phys., 14 [3] 439-46 (2014).

71. T. Yu, X. Cheng, X. Zhang, L. Sui, Y. Xu, S. Gao, H. Zhao, and L. Huo, "Highly Sensitive $\mathrm{H}_{2} \mathrm{~S}$ Detection Sensor at Low Temperature Based on Hierarchically Structured NiO Porous Nanowall Arrays," J. Mater. Chem. A, 3 11991-99 (2015).

72. B. Fromme, d-d-Excitations in Transition-Metal Oxides: A Spin Polarized Electron Energy Loss (SPEELS) Spectroscopy Studies; Verlag Berlin Heidelberg, New York, 2001.

73. N. Ajoudanian and A. N. Jhieh, "Enhanced Photocatalytic Activity of Nickel Oxide Supported on Clinoptilolite Nanoparticles for the Photodegradation of Aqueous Cephalexin," Mater. Sci. Semicond. Process., 36 162-69 (2015). 
74. C. Cantalini, M. Post, D. Buso, M. Guglielmi, A. Martucci, "Gas Sensing Properties of Nanocrystalline $\mathrm{NiO}$ and $\mathrm{Co}_{3} \mathrm{O}_{4}$ in Porous Silica Sol-Gel Films," Sens. Actuators, B, 108 [1-2] 184-92 (2005).

75. J. A. Dirksen, K. Duval, and T. A. Ring, "NiO Thin-Film Formaldehyde Gas Sensor," Sens. Actuators, B, 80 [2] 106-15 (2001).

76. N. Miura, J. Wang, M. Nakatou, P. Elumalai, S. Zhuiykov, and M. Hasei, "High Temperature Operating Characteristics of Mixed-Potential-Type $\mathrm{NO}_{2}$ Sensor Based on StabilizedZirconia Tube and NiO Sensing Electrode," Sens. Actuators, B, 114 [2] 903-9 (2006).

77. C. Y. Lee, C. M. Chiang, Y. H. Wang, and R. M. Ma, "A Self-Heating Gas Sensor with Integrated NiO Thin-Film for Formaldehyde Detection," Sens. Actuators, B, 122 [2] 503-10 (2007).

78. C. Luyo, R. Ionescu, L. F. Reyes, and Z. Topalian, "Gas Sensing Response of NiO Nanoparticles Films Made by Reactive Gas Deposition," Sens. Actuators, B, 138 [1] 1420 (2009).

79. C. Balamurugan, Y. J. Jeong, and D. W. Lee, "Enhanced $\mathrm{H}_{2} \mathrm{~S}$ Sensing Performance of a p-type Semiconducting PdO-NiO Nanoscale Heteromixture," Appl. Surf. Sci., 420 638-50 (2017).

80. V. D. Kapse, S. A. Ghosh, G. N. Chaudhari, F. C. Raghuwanshi, and D. D. Gulwade, " $\mathrm{H}_{2} \mathrm{~S}$ Sensing Properties of La-Doped Nanocrystalline $\mathrm{In}_{2} \mathrm{O}_{3}$, , Vacuum, 83 [2] 346-52 (2009).

81. S. Cho, J. Ma, Y. Kim, Y. Sun, G. Wong, and J. Ketterson, "Photoluminescence and Ultraviolet Lasing of Polycrystalline ZnO Thin Films Prepared by the Oxidation of the Metallic Zn,” Appl. Phys. Lett., 752761 (1999).

82. T. Yamamoto, T. Shiosaki, and A. Kawabata, "Characterization of $\mathrm{ZnO}$ Piezoelectric Films Prepared by rf Planarmagnetron Sputtering,” J. Appl. Phys., 51 3113-20 (1980).

83. K. Keis, E. Magnusson, H. Lindstorm, S. E. Lindquist, and A. Hagfeldt, "A 5\% Efficient Photoelectrochemical Solar Cell Based on Nanostructured ZnO Electrodes," Sol. Energy Mater. Sol. Cells, 73 [1] 51-8 (2002).

84. H. Xu, X. Liu, D. Cui, M. Li, and M. Jiang, "A Novel Method for Improving the Performance of ZnO Gas Sensors," Sens. Actuators, B, 114 [1] 301-7 (2006).

85. N. V. Hieu, N. D. Khonang, D. D. Trung, L. D. Toan, and N. V. Duy, "Comparative Study on $\mathrm{CO}_{2}$ and CO Sensing Performance of LaOCl-Coated ZnO Nanowires," J. Hazard Mater., 244 209-16 (2013).

86. G. Centi, G. Golonelli, and G. Busca, "Modification of the Surface Pathways in Alkane Oxidation by Selective Doping of Broensted Acid Sites of Vanadyl Pyrophosphate," J. Phys. Chem., 94 [17] 6813-19 (1990).

87. P. Conception, A. Galli, J. M. Lopez Nieto, A. Dejoz, and M. I. Vazquez, "On the Influence of the Acid-Base Character of Catalysts on the Oxidative Dehydrogenation of Alkanes," Top. Catal., 3 [3-4] 451-60 (1996).

88. J. C. Vedrine, J. M. M. Millet, and J.-C. Volta, "Molecular Description of Active Sites in Oxidation Reactions: AcidBase and Redox Properties, and Role of Water," Catal. Today, 32 [1-4] 115-23 (1996).

89. D. H. Kim, J. Y. Yoon, H. C. Park, and K. H. Kim, " $\mathrm{CO}_{2}$ Sensing Characteristics of $\mathrm{SnO}_{2}$ Thick Film by Coating Lanthanum Oxide," Sens. Actuators, B, 62 [1] 61-6 (2000).

90. A. Marsal, A. Cornet, and J. R. Morante, "Study of the CO and Humidity Interference in La Doped Tin Oxide $\mathrm{CO}_{2}$ Gas Sensor," Sens. Actuators, B, 94 [3] 324-29 (2003).

91. C.-Y. Kim, J. W. Elam, P. C. Stair, and M. J. Bedzyk, "Effects of Off-Stoichiometry of $\mathrm{LiC}_{6}$ on the Lithium Diffusion Mechanism and Diffusivity by First Principles Calculations," J. Phys. Chem. C, 114 2375-79 (2010).

92. S. Zafeiratos, F. E. Paloukis, M. M. Jaksic, and S. G. Neophytides, "Thermal Stability of Electrodeposited Nickel on Vanadium: Evidence for Oxygen Diffusion and Intermetallic Phase Formation," Surf. Sci., 552 [1-3] 215-28 (2004). 